\title{
Contemporaneous and Lagged Effects of Life Domains and Substance Use: A Test of Agnew's General Theory of Crime and Delinquency
}

\author{
Fawn T. Ngo ${ }^{1}$ and Raymond Paternoster ${ }^{2}$ \\ ${ }^{1}$ College of Arts \& Sciences, Division of Criminology, University of South Florida Sarasota-Manatee, 8350 N. Tamiami Trail, \\ Sarasota, FL 34243, USA \\ ${ }^{2}$ Department of Criminology and Criminal Justice, University of Maryland, 2129 LeFrak Hall, College Park, MD 20741, USA
}

Correspondence should be addressed to Fawn T. Ngo; fawnngo@sar.usf.edu

Received 30 September 2013; Revised 30 November 2013; Accepted 2 December 2013; Published 27 January 2014

Academic Editor: Kevin M. Beaver

Copyright @ 2014 F. T. Ngo and R. Paternoster. This is an open access article distributed under the Creative Commons Attribution License, which permits unrestricted use, distribution, and reproduction in any medium, provided the original work is properly cited.

\begin{abstract}
This study presents a partial test of Agnew's general theory of crime and delinquency. Relying on a sample of adolescents and employing measures of the self, family, school, and peers domains, this study examines the contemporaneous and lagged effects of these four life domains on the likelihood of consuming alcohol and using marijuana. This study also assesses the contemporaneous and lagged effects of the life domain variables on themselves and on one another. Overall, the results lend support for Agnew's general theory. The results also reveal several notable puzzles and underscore the complexity of this potentially important contemporary theoretical perspective.
\end{abstract}

\section{Introduction}

In 2005, Robert Agnew introduced his general theory of crime and delinquency with the publication of Why Criminals Offend: A General Theory of Crime and Delinquency. Agnew's general theory is an integrated inductive theory built upon a foundation of empirical research findings of the causes of crime with a focus on those variables having direct effects on crime and the relationship among them (for a discussion of this type of theoretical integration, see [1]). At the heart of the theory are five clusters or "life domains" of variables and each one Agnew claims has been proven to be a robust correlate of crime. These five domains-self, family, peers, school, and work-represent the best known covariates in the existing literature for explaining why some individuals are more likely to engage in crime than others. Agnew's risk-factor based general theory was intended to account for between-individual differences in the risk of committing crime. Agnew's general theory is an even more ambitious theory in that it seeks to account for all types of crime, address the "known facts" of crime, explicate micro- and macro patterns of crime, and guide policies in preventing and controlling crime [2].

Accordingly, Agnew's general theory represents a potentially important contribution to the field of criminology and knowledge about crime and criminals. However, to date, there has only been one published test of Agnew's theory and even these researchers were only able to provide a partial test of his perspective [3]. This fact is understandable since Agnew's theory is a complex one and even Agnew [2, page 185] himself acknowledges that:

At present, however, there are few data sets that allow for anything close to a full test. Also, a full test would impose large demands on the data and computational programs, as large number of effects require estimation, including reciprocal, nonlinear, and interactional effects. Given these facts, the general theory is probably best tested in bits and pieces.

In the current study, we extend the work undertaken by previous researchers as well as follow Agnew's suggestion 
for modesty by only examining portions of the theory. In particular, we seek to assess the contemporaneous and lagged effects of the life domains on crime and the contemporaneous and lagged effects of the life domains on themselves. The rest of our paper is organized as follows: first, we describe Agnew's general theory and review the previous empirical test of the theory; next, we outline our hypotheses and present our methodology; finally, we discuss our findings and their implications.

\section{Agnew's General Theory of Crime and Delinquency}

Agnew's general theory commences with the fundamental idea that crime is most likely to occur when the constraints against crime are low and the motivations for crime are high [2, page 17-33]. From this fundamental premise, the assertion is that a host of individual and social causal variables affect the constraints against and the motivations for crime (for a complete list of these variables, see [2, Chapter 2]). However, he argues that it would be futile to attempt to group these variables by the type of constraint or motivation they index because many of these variables affect both the constraints against and the motivations for crime. Accordingly, Agnew [2, pages 42-55] resolved to group these variables into clusters organized around five major age-graded life domains: self, family, school, peers, and work. These life domains are argued [2, page 40] to "represent the major spheres of life and they encompass all of the direct causes of crime."

The life domain of self consists of individual-level personality traits with impulsivity and irritability being the most relevant. The family domain includes such components as the emotional attachment between parent and children, the presence of parental conflict or child abuse, the amount of supervision exercised over children, the warmth or absence of warmth between parents, and parental criminality. The domain of school comprises such variables as school success, involvement in school activities, emotional attachment with teachers, and negative treatment by teachers. The peer domain includes the involvement of one's peers in deviance, the emotional bond with peers, and the amount of unsupervised activities with peers. Finally, the work domain includes factors such as unemployment, poor working conditions, the criminality of coworkers, and the presence or absence of conflict with coworkers. Agnew defended his grouping scheme by stressing that "Grouping the causes of crime in this manner allows us to ensure that each cause is part of one and only one category" [2, page 40] and "because the variables in each domain are caused by many of the same factors and have large causal effects on one another" [4, page 594].

2.1. The Five Life Domains: Self, Family, School, Peers, and Work. The five life domains in Agnew's general theory are age-graded-some of them are more important at particular periods of life and less important or irrelevant at others. Specifically, among children, Agnew [2, pages 56-59] claims that irritability/low self-control would have the largest effects on crime, while among adolescents he argues that both irritability/low self-control and peer delinquency have the largest impacts on crime, and among adults he added poor or no marriage and no or poor employment. In the domain of "self", Agnew posits that low self-control and the personality trait of "irritability" constitute the key variables that directly weaken the constraints against and strengthen the motivations for crime. Individuals with low self-control are impulsive, have a preference for exciting and risky activities, are generally unconcerned with the feelings and rights of others, and often respond to the temptations of the moment without any regards for the long-range of consequences [5]. Similarly, individuals who possess the trait of irritability tend to experience events as aversive, have an antagonistic interactional style, show little concern for the feelings and rights of others, and often attribute events to the malicious behavior of others (they believe that others are "out to get them" $[6,7])$. Among the major traits that comprise the human personality, low self-control and irritability emerge as the leading personality traits that cause crime. Irritable individuals and individuals with low self-control tend to exhibit low internal control, are more likely to interpret certain situations as stressful, experience intense emotional reactions to such situations, respond to such situations in an aggressive manner, hold beliefs that justify aggressive behavior, and often perceive crime as rewarding [6, 8-11].

In the domain of "family," Agnew claims that negative bonding between parent and child, poor supervision/discipline, family conflict and abuse, the absence of positive parenting, and criminal parents/siblings are the main causes of crime for those who are younger. For adults, however, Agnew replaces these factors with the functionally equivalent variables of failing to marry or divorce/separation, negative bonding to spouse/partner, family conflict, poor spouse/partner supervision, and having a criminal spouse or partner.

Negative bonding between child and parent occurs when family members reject one another and spend little time together in pleasurable activities. Parents with poor supervision/discipline skills are those who fail to set clear rules prohibiting deviant and antisocial behaviors, effectively monitor rule compliance, and consistently discipline the child in an appropriate manner for rule violations. The absence of positive parenting refers to parents who fail to teach their children social skills so the children could form close ties to conventional others, academic skills so the children could excel in school, and problem-solving skills so the children could resolve problems in a nondelinquent manner. Family conflict involves threats and violence (both emotional and physical) among family members and child abuse includes not only physical, sexual, and emotional abuses but also child neglect and maltreatment. Criminal parents and siblings sometimes provide deliberate instruction on crime, including beliefs favorable to crime and negative reinforcement for crime [2].

Family research in criminology suggests that the variables listed above have relatively moderate to large direct effects on crime and delinquency. In particular, they reduce one's stake in conformity, function as a major source of strain, reduce legitimate coping resources, foster the social learning 
of crime, and reinforce crime and delinquency. For instance, negative bonding between child and parent frees a child from conventional constraints and when the child's stake in conformity is weakened, delinquent behavior becomes more likely [12-14]. Negative bonding between child and parent is also a major source of strain and will lead to crime and delinquency in the absence of effective legitimate coping resources [15]. Poor parental supervision/discipline and family conflict and abuse also reduce a child's stake in conformity, increase strain $[15,16]$, and foster the social learning of crime (e.g., parents who employ harsh punishments provide aggressive models for their children and implicitly teach the children that violence is an appropriate response to certain problems $[16,17])$. Likewise, having criminal parents fosters the social learning of crime because parents model criminal behavior for their children, instill beliefs favorable to crime in their children, and demonstrate negative reinforcement for crime [18-20].

Concerning the relationships between family factors and adult crime, the evidence suggests that adults who are unmarried or negatively bonded to their spouses/partners have higher levels of crime relative to adults who are married or positively bonded to their spouses/partners (i.e., individuals who love and respect their spouses, individuals who engage in positively valued activities with their spouses [21-24]). Research evidence also reveals that the amount of supervision exercised by one's spouse (i.e., the extent to which the spouse expresses disapproval of crime and related behaviors, monitor his/her partner' behavior, and sanction criminal behavior in an appropriate manner) is related to crime and having a criminal spouse or partner increases the likelihood of crime, especially for women. The amount of conflict and abuse between spouses also affect crime and the effects of these variables on crime follow the same pattern as the effects of parental conflict and abuse on juvenile delinquency [25].

Within the domain of "school," Agnew recognizes that negative bonding to teachers/school, poor academic performance, negative treatment by teachers, little time on homework, low educational and occupational goals, and poor supervision/discipline are the major correlates of crime. Negative bonding to teachers/school occurs when students express that they hate teachers and school, dislike the time they spend at school, and getting nothing of value from school. Students with poor academic performance are those with low scores on standardized tests, having poor grades, and being held back in school. Students experience negative treatment by teachers when the teachers "talk down" to them, verbally abuse or insult them, threaten them, or treat them unfairly. Schools with poor supervision/discipline are those that fail to clearly communicate to students the expected rules for behavior, monitor behavior among students, reinforce conventional behavior and sanction rule violations in a consistent and appropriate manner. Students with low educational and occupational goals generally do not have a desire to attend college or to obtain prestigious jobs [2].

Similar to the family variables, the school variables listed above have been demonstrated to have relatively moderate to large direct effects on delinquency. In particular, negative bonding to teachers/school reduces a child's stake in conformity as well as contributes to strain [26,27]. Similarly, negative treatment by teachers and poor supervision/discipline serve as major sources of strain for students while poor supervision/discipline also weakens external control and negative treatment by teachers also fosters the social learning of crime by providing negative models and implicitly teaching students that aggressive behavior is acceptable $[28,29]$. Poor academic performance, little time spent on homework, and low educational and occupational goals also lead to delinquency by reducing students' stake in conformity and increasing their strain $[29,30]$. Among adults, since most are not in school, Agnew theorizes that crime will be higher among those with limited education. However, the effect of limited education on crime will be indirect in that limited education will affect crime "primarily through its effect on the individual's work, marital life, and peer associations" [2, page 51].

For the domain of "peers," Agnew maintains that having delinquent peers, having frequent conflicts with one's peers and being abused by them, and spending much time with peers in unstructured and unsupervised activities are the main factors impacting delinquency. There is much evidence indicating that associating with delinquent peers is the most important predictor of delinquency other than prior delinquency [27, 31-38]. Having delinquent friends not only reduces one's stake in conformity (engaging in delinquent activities is not going to jeopardize a youth's relationship with his/her delinquent friends) but also increases strain (delinquent friends often abuse one another and get into conflicts with each other) and foster the social learning of crime (delinquent friends are more likely to reinforce crime, model crime, and teach beliefs favorable to crime [2]). Associating with delinquent peers also impacts youths' concern with external sanctions because they seldom see the crime committed by their friends being sanctioned [39, 40].

Being verbally and physically abused by peers and the experience of criminal victimization could also increase the likelihood of offending. Peer conflict and abuse reduce one's stake in conformity (decrease one's ties to others) and increase strain while criminal victimization fosters the social learning of crime (when abused individuals are exposed to aggressive or criminal models they develop beliefs favorable to crime such as society is a "jungle" and only the strong survive $[18,27,30,33,36,41])$. Youths who spend unstructured, unsupervised time with peers are also more likely to engage in delinquent activities relative to youths who do not spend unstructured and unsupervised time with their peers because the former are more likely to encounter situations conducive to crime (situations in which external control is low, when peers reinforce crime, model crime, and present beliefs favorable to crime $[42,43])$. Among adults, Agnew suggests that although they are less likely to have criminal friends due to their work and marital commitments, peers will continue to play a major role in the lives of those who are unmarried, unemployed, or employed in "bad jobs" [4].

Finally, within the domain of "work," unemployment, poor work performance and working conditions, poor supervision and discipline, negative bonding to work, and criminal coworkers are the significant variables affecting 
crime. Although the concept of unemployment is sometimes measured imprecisely by previous researchers (e.g., studies that compare unemployed individuals with individuals in all types of jobs), research evidence suggests that unemployment increases the likelihood of certain types of crime. Unemployment, in particular long-term unemployment with little prospect for future work, reduces one's stake in conformity, contributes to strain, and increases exposure to situations conducive to strain (individuals without a job "hanging out" on the street with peers $[22,23,44-49])$. There is also evidence that crime is more likely among individuals who work in environments that lack clear rules regarding appropriate behavior, where behavior is poorly monitored and where rule violations are seldom sanctioned in an appropriate manner (i.e., environments with poor supervision/discipline [50]).

Studies examining the relationship between work and adult crime indicate that relative to individuals with positive bonding to work, individuals with negative bonding to work (individuals who dislike their work and their coworkers) are more likely to engage in crime because they have a lower stake in conformity and are higher in strain. Individuals with criminal coworkers are also more likely to engage in crime relative to individuals with prosocial coworkers because criminal coworkers potentially reinforce crime, model crime, and teach beliefs favorable to crime $[23,51,52]$.

2.2. The Role of Prior Crime. Agnew also recognizes the important role of prior crime. Agnew's general theory delineates that prior crime has both direct and indirect effects on subsequent crime. Prior crime is theorized to indirectly impact subsequent crime when it affects certain constraints against or motivations for crime. For instance, engaging in illicit activities such as drugs may lead to monetary strain (i.e., a desperate need for cash), which is a motivation for crime. Agnew also drew from labeling theory $[53,54]$ in accounting for the indirect effect of prior crime on subsequent crime. In particular, he argues that prior crime increases the likelihood of subsequent crime when individuals who are labeled as "criminals" or "bad people" end up associating with each other as a result of being rejected by conventional others. Associating with criminal others, in turn, decreases the constraints against and increases the motivations for crime [2].

Prior crime also indirectly affects subsequent crime through the five life domains. As an example, engaging in delinquent activities may lead to weak bonds between parents and children, increase the likelihood of poor parental supervision, and/or cause parents to treat their children in a harsh manner. These factors in turn contribute to subsequent delinquent behavior. This indirect process is harmonious with the "knifing off" of conventional opportunities described by Sampson and Laub [23] and the "snares" that lead to persistent offending described by Moffitt [55]. Notably, Agnew's general theory does not posit that engaging in crime always increases the chances of subsequent crime. In fact, the theory argues that, in some cases, prior crime has no effect on crime or even may reduce the likelihood of further crime. In these cases, the theory claims that how others react to the individual's crime and the characteristics of the criminal are the determining factors (for a comprehensive description of these factors, see [2, Chapter 5]).

To summarize, Agnew's age-graded general theory is an amalgamation of the major correlates of crime, with a focus on those variables having moderate to strong direct effects on crime and the relationship among those variables. At the heart of the theory are five clusters or life domains of variables-self, family, peers, school, and work-representing the explanation for why some individuals are more likely to engage in crime than others. Among other things, therefore, the theory was designed to explain between-individual differences in criminal offending.

\section{Prior Research}

To the best of our knowledge, to date, there has only been one published test of Agnew's general theory, perhaps not surprising given the complexity of the theory and the great demands on the data to test it. However, prior research examining the relationships between risk and protective factors and adolescent problem behavior has shown that numerous factors across several life domains are related to a range of adolescent problem behavior. For instance, within the family domain, parental substance use, family conflict, and poor family management practices have been documented as the main risk factors affecting substance use, violence, and delinquency among adolescents [56-58]. Within the domain of school, factors including academic failure, commitment to school, and disengagement from school are significant predictors of adolescent problem behavior [59-61]. Similarly, within the self domain, personality factors such as sensation seeking, poor impulse control, and conscientiousness have been linked to adolescent negative outcomes $[62,63]$.

Utilizing data from a sample of male adult offenders participated in the Maryland boot camp experiment, Ngo et al. [3] provided a partial test of Agnew's general theory. In particular, the researchers examined whether each of the five life domain variables at the core of Agnew's theory is related to recidivism, whether there is a nonlinear relationship between the life domains and recidivism, and whether the five life domains interact in causing recidivism. To represent the domain of self, the researchers utilized Grasmick et al.s [8] twenty-four-item self-control scale and, for the family domain, they employed the measures of no marriage (whether the respondent was married or not) and bad relationship (the respondent's perception of his relationship and activities with his spouse or significant other). Regarding the school domain, they used the measure of limited education (whether the respondent graduated from high school or not) and for the peers domain, they relied on the measure of friends' antisocial behaviors/attitudes (the respondent's perceptions of their friends' attitudes). The researchers also employed two indicators to represent the work domain: no job (the respondent's employment status before being incarcerated) and bad job (the respondent's perception of his last job).

Overall, Ngo and colleagues [3] found limited support for Agnew's general theory. More specifically, they uncovered 
that only two of the five life domains, having a bad job and being a high school dropout, were significantly related to recidivism. Additionally, with the exception of the peers domain, they failed to find the predicted nonlinear relationship between the life domains and recidivism. The researchers also reported that while 7 of the 21 interaction effects were significantly related to recidivism at the bivariate level, none of the two-way bivariate interactions was significant in a multivariate linear probability model.

Notwithstanding Ngo and colleagues' efforts at providing the very first empirical test of Agnew's general theory, their study was limited due to a number of issues. First, the sample included in their study was a very specific and narrow sample (i.e., primarily young African Americans adult males convicted of drug crimes). Second, the researchers only examined lagged (delayed) effects between the life domains and crime. Third, the outcome variable in their study was recidivism but Agnew's theory appears to emphasize the onset of offending. Fourth, their test involved a limited number of variables within each domain. In this study, we seek to build upon and extend this research by examining both the contemporaneous and lagged effects of the life domains and adolescent substance use. We also draw data from a nationally representative sample of adolescents and expand the specific variables in each life domain. In particular, our focus in this paper is on assessing the sixth proposition of Agnew's general theory [2, page 121] that stipulates that the life domains have largely contemporaneous effects on one another and on adolescent substance use as well as each life domain has a large lagged effect on itself.

\section{Research Hypotheses}

As stated previously, Agnew's general theory posits that crime is caused by five clusters or life domains of variables, self, family, peers, school, and work. Further, the effects of the specific variables on crime will vary over the life course depending on the individual's stage in life (i.e., childhood, adolescence and adulthood). With regard to adolescents-who comprise the sample for the present study-the theory suggests that the variables with the greatest impact on antisocial behavior like crime and substance use include irritability/low selfcontrol, poor parenting, negative school experiences, and peer delinquency [2, page 58]. It is noteworthy that the work domain is not included here because according to Agnew [2], the work domain is more relevant to adults than children and adolescents. Pertaining to the effect of the life domains on crime, Agnew maintains that "The life domains affect crime, the life domains affect one another, crime affects the life domains, and prior crime affects subsequent crime" [2, page 121]. Agnew further stipulates that the life domains have largely contemporaneous effects on crime and one another and each life domain has a large lagged effect on itself, but the life domains do not have large lagged effects on crime nor on one another. While Agnew refers generically to crime in most of his writings, we address the issue of the relationship between his life domains and adolescent substance use.

To assess the contemporaneous effects (Agnew [2] defines contemporaneous effects as those that occur within a few months' time and since our data only include substance use that occurred within the last 30 days and within the last 12 months, we selected the former to investigate the contemporaneous effect of the life domains on crime) of the life domains on adolescent substance use, we hypothesize the following.

H1: Time 1 life domain variables are significantly related to Time 1 substance use.

Since Agnew [2] claims that the life domains do not have large lagged effects on crime, we hypothesize the following.

H2: The effects of Time 1 life domain variables on Time 2 substance use are smaller relative to the effects of Time 1 life domain variables on Time 1 substance use.

To examine the contemporaneous effects of the life domains on one another, we hypothesize the following.

H3: Time 1 life domain variables are significantly related to the other Time 1 life domains variables.

To assess the lagged effects of the life domains on themselves, we hypothesize the following.

H4: Time 1 life domain variables are significantly related to the same Time 2 life domain variables.

Finally, given Agnew's [2] proposition that the life domains do not have large lagged effects on one another, we hypothesize the following.

H5: The effects of Time 1 life domain variables on the other Time 2 life domain variables are smaller relative to the effects of Time 1 life domain variables on the other Time 1 life domain variables.

\section{Data and Methods}

Data for the current study come from the National Education Longitudinal Study (NELS), a project designed to provide data on students' experiences as they leave elementary school and progress through secondary and postsecondary education or their careers [64]. NELS is a nationally representative data set with student, parent, teacher, and school administrator components. The first wave of the study occurred in 1988 , when approximately 25,000 eighth-grade students were randomly selected from more than 1,000 private and public schools across the US. More specifically, the study employed a two-stage stratified sample design with schools chosen at the first stage and students within schools chosen at the second stage. The student sample was surveyed again in the tenth (1990) and twelfth grades (1992), and follow-up surveys were also conducted at 2 (1994) and 8 years (2000) after the scheduled date of high school graduation.

One unique aspect of the NELS is that, at each wave of data collection, students who dropped out of the sample were replaced with students who shared similar demographic characteristics. This "refreshment" subsample allows the NELS to continue to employ a nationally representative sample of students in the US. Furthermore, data from parents 
were collected during the second and third waves (1990 and 1992) and school characteristics, official transcripts, and standardized tests were gathered from school administrators. In addition to parents, school teachers were also surveyed by mail regarding the behavior of students in their classes during the second and third waves (1990 and 1992) of the study. We capitalize on the longitudinal nature of the NELS data by utilizing variables measured during the baseline wave (1988; hereafter, T0) and the first (1990; hereafter, T1) and second (1992; hereafter, T2) follow-up waves of the study. We also draw data gathered from school teachers. Before we delineate our variables and measures, we provide a description of our sample.

5.1. Sample. Our panel sample includes the same students who participated at baseline (T0) and both the first (T1) and second follow-up (T2) waves of the study. That is, our study excludes respondents in the "refreshment" subsamples. After taking into account attrition and missing values on the dependent variables, the sample size was reduced to 9,244 . Additionally, we lost a significant number of cases as a result of teachers who failed to return their surveys. In particular, approximately $12.5 \%$ of teachers failed to return their surveys during the first follow-up study (T1) and 24\% of teachers did not return their surveys during the second follow-up study (T2). To determine whether students with missing data on teacher-rated effort had different levels of delinquent behavior relative to students with valid data, we conducted a mean comparison between those retained in the sample and those lost to attrition. With one exception, the means between the two groups of respondents on both Time 1 and Time 2 measures of drinking alcohol and using marijuana (the proportions of students who drank alcohol and used marijuana) were very comparable (It is noteworthy that independent sample $t$-tests are not informative here since with samples sizes of several thousand even very trivial differences will be statistically significant). For example, the proportion of retained subjects who reported ever drinking alcohol at Time 1 was 0.43 , and it was 0.39 for those lost to attrition. On the other hand, the proportions reporting marijuana use were 0.05 for the retained subjects and 0.09 for those lost to attrition. At Time 2 the proportion drinking alcohol was 0.51 in both the retained and attrition group, and 0.09 of those retained in the sample reported marijuana use compared with 0.10 for those lost to attrition. Additionally, to retain sufficient sample size, we employed all available valid data during each wave of the study. After taking into account missing data on teacher-rated effort, the sample size for the T1 sample encompasses 8,087 students and the sample size for the T2 sample includes 6,146 students (It is noteworthy that others who have used the NELS data to study crime have had the same problem of sample attrition over time and missing data (see $[65,66]))$.

Table 1 shows the demographic and other characteristics of the two samples. As shown in Table 1, slightly less than half of the students (47\%) in the T1 sample were males and the majority of the students were Caucasians (73\%). The majority of students in the $\mathrm{T} 1$ sample also attended public schools (86\%) located in the suburbs and many of the students (41\%) had parents with some college education. Further, on average, the students tended to come from families with moderate socioeconomic status (The variable, "family SES quartile," was constructed using the socioeconomic status data reported in NELS: Quartile 1 (low SES quartile), Quartile 2, Quartile 3, and Quartile 4 (high SES quartile). For the current study, Quartiles 2 and 3 were combined to represent the moderate SES quartile). The demographics of the T2 sample appear to parallel those in the T1 sample. Similar to the T1 sample, almost half (49\%) of the students in the T2 sample were males and the majority of the students were Caucasians (71\%). The majority of the students also attended public schools (84\%) located in suburban areas and many of the students (39\%) also had parents with some college education. Finally, the mean socioeconomic quartile for students in the T2 sample was the medium quartile (see Table 1).

\subsection{Measurement of Variables}

5.2.1. Substance Use. Five measures of substance use were included in the study (see Table 1. To be consistent, all of our delinquency measures involve the use of tobacco, alcohol, and drugs by youths). The first variable, T0 prior smoking cigarettes, was measured at baseline (1988) using the question, "How many cigarettes do you usually smoke a day?" This variable was coded as a dichotomous variable with $1=$ the student reported smoking at least one cigarette a day and $0=$ the student did not smoke cigarettes. The second and third variables, T1 drank alcohol and T1 used marijuana, were measured during the first follow-up survey of NELS (1990). Students were asked to indicate the number of times they drank alcohol in the last 30 days and the number of times they used marijuana in the last 30 days. T1 drank alcohol and T1 used marijuana were coded as dichotomous variables with $1=$ the student consumed alcohol or used marijuana in the last 30 days and $0=$ the student did not consume alcohol or used marijuana in the last 30 days. The descriptive statistics for the above variables are listed in Table 1.

Information on the fourth and fifth variables, T2 drank alcohol and T2 used marijuana, came from the second followup survey of NELS (1992). T2 drank alcohol was measured using a single question that asks students to indicate the number of times they drank alcohol in the last 30 days and T2 used marijuana was also measured using a question that asks students to indicate the number of times they used marijuana in the last 30 days. Similar to the other substance use variables, these two measures were coded as dichotomous variables with $1=$ the student drank alcohol or used marijuana in the last 30 days and $0=$ the student did not drink alcohol or used marijuana in the last 30 days. Table 1 shows the descriptive statistics for these variables.

5.2.2. Life Domains. A number of variables were selected to represent the four life domains of Agnew's theory (for the list of suggested variables within each life domain, see Agnew, [2, page 38]). (Recall that, given our sample of adolescents, the work domain is excluded from the current study). Cronbach's alpha was also computed for each scale in each life domain 
TABLE 1: Descriptive statistics of samples.

\begin{tabular}{|c|c|c|c|c|}
\hline & $N$ & Mean/\% & SD & Range \\
\hline \multicolumn{5}{|l|}{ Time 1 demographics } \\
\hline Gender $(1=$ male; $0=$ female $)$ & 8087 & 0.47 & 0.50 & $0-1$ \\
\hline \multicolumn{5}{|l|}{ Race } \\
\hline African American $(1=\mathrm{AA} ; 0=$ other race $)$ & 8056 & 0.08 & 0.27 & $0-1$ \\
\hline White $(1=$ white; $0=$ other race $)$ & 8056 & 0.73 & 0.44 & $0-1$ \\
\hline \multicolumn{5}{|l|}{ Parent education } \\
\hline Less than high school & 613 & 0.08 & & \\
\hline High school grad/GED & 1541 & 0.19 & & \\
\hline Some college & 3280 & 0.41 & & \\
\hline Bachelor degree & 1287 & 0.16 & & \\
\hline Master degree or equivalent & 788 & 0.10 & & \\
\hline Ph.D./M.D./other & 455 & 0.06 & & \\
\hline Family SES quartile $(1=$ low; $2=$ medium; $3=$ high $)$ & 7966 & 2.09 & 0.70 & $1-3$ \\
\hline School type $(1=$ public; $0=$ private $)$ & 8087 & 0.86 & 0.35 & $0-1$ \\
\hline School area $(1=$ urban; $2=$ suburban; $3=$ rural $)$ & 8074 & 2.06 & 0.77 & $1-3$ \\
\hline Time 1 victimization & 8056 & 0.57 & 0.50 & $0-1$ \\
\hline \multicolumn{5}{|l|}{ Time 2 demographics } \\
\hline Gender $(1=$ male; $0=$ female $)$ & 6070 & 0.49 & 0.50 & $0-1$ \\
\hline \multicolumn{5}{|l|}{ Race } \\
\hline African American $(1=\mathrm{AA} ; 0=$ other race $)$ & 6062 & 0.09 & 0.28 & $0-1$ \\
\hline White $(1=$ white; $0=$ other race $)$ & 6062 & 0.71 & 0.45 & $0-1$ \\
\hline \multicolumn{5}{|l|}{ Parent education } \\
\hline Less than high school & 303 & 0.06 & & \\
\hline High school grad/GED & 1105 & 0.18 & & \\
\hline Some college & 2351 & 0.39 & & \\
\hline Bachelor degree & 1096 & 0.18 & & \\
\hline Master degree or equivalent & 678 & 0.11 & & \\
\hline Ph.D./M.D./other & 497 & 0.07 & & \\
\hline Family SES quartile $(1=$ low; $2=$ medium; $3=$ high $)$ & 5952 & 2.16 & 0.70 & $1-3$ \\
\hline School type $(1=$ public; $0=$ private $)$ & 6058 & 0.84 & 0.37 & $0-1$ \\
\hline School area $(1=$ urban; $2=$ suburban; $3=$ rural $)$ & 6044 & 2.02 & 0.77 & $1-3$ \\
\hline \multicolumn{5}{|l|}{ Substance use } \\
\hline T0 prior smoking cigarettes $(1=$ yes; $0=$ no $)$ & 7702 & 0.04 & 0.19 & $0-1$ \\
\hline T1 drank alcohol $(1=$ yes; $0=$ no $)$ & 7332 & 0.41 & 0.49 & $0-1$ \\
\hline $\mathrm{T} 1$ used marijuana $(1=$ yes; $0=$ no $)$ & 7484 & 0.06 & 0.24 & $0-1$ \\
\hline T2 drank alcohol $(1=$ yes; $0=$ no $)$ & 5403 & 0.50 & 0.50 & $0-1$ \\
\hline $\mathrm{T} 2$ used marijuana $(1=$ yes; $0=$ no $)$ & 5233 & 0.09 & 0.28 & $0-1$ \\
\hline \multicolumn{5}{|l|}{ Time 1 life domains } \\
\hline T1 low self-control & 8085 & 9.4 & 3.08 & $1-30$ \\
\hline $\mathrm{T} 1$ attitudes favorable to deviance & 8067 & 22.34 & 5.80 & $9-64$ \\
\hline $\mathrm{T} 1$ close communication with parents & 7441 & 11.52 & 2.64 & $1-18$ \\
\hline T1 poor supervision/discipline & 7569 & 16.83 & 4.19 & $1-28$ \\
\hline $\mathrm{T} 1$ negative treatment by teacher & 7996 & 1.94 & .68 & $1-4$ \\
\hline T1 negative attachment to school & 8015 & 6.41 & 1.59 & $1-12$ \\
\hline T1 low educational goals & 8012 & 3.45 & 2.00 & $1-9$ \\
\hline T1 homework time & 6934 & 5.14 & 2.51 & $0-14$ \\
\hline $\mathrm{T} 1$ conventional peers & 7742 & 8.50 & 2.07 & $1-15$ \\
\hline
\end{tabular}


TABle 1: Continued.

\begin{tabular}{|c|c|c|c|c|}
\hline & $N$ & Mean/\% & SD & Range \\
\hline \multicolumn{5}{|l|}{ Time 2 life domains } \\
\hline T2 low self-control & 6104 & 9.44 & 2.90 & $1-24$ \\
\hline T2 close communication with parents & 5416 & 12.62 & 2.93 & $2-18$ \\
\hline T2 negative attachment to school & 6055 & 3.99 & 1.09 & $2-8$ \\
\hline T2 low educational goals & 4929 & 2.42 & 1.71 & $1-9$ \\
\hline T2 homework time & 5410 & 6.53 & 2.79 & $0-14$ \\
\hline $\mathrm{T} 2$ conventional peers & 5767 & 11.54 & 2.08 & $1-15$ \\
\hline
\end{tabular}

to assess their internal consistency (It appears that Agnew [2] endorses both the combination of variables within each life domain into scales as well as the analyses of specific variables in each life domain scale. Agnew maintained that, "While combining these variables into more general scales greatly simplifies the general theory, it does result in the loss of certain information. Most notably, we lose information on the relative effects of the specific variables on one another" [2, page 178]. He also noted that "Knowing that certain variables have relatively large effects on others is useful to policy makers, because this information can help them target key variables in prevention and rehabilitation programs" [2, page 178]. For the current study, we construct scales when there are sufficient items to do so. Otherwise, we analyze specific variables within each life domain). Our self domain is represented by three measures, T1 low self-control, T2 low self-control, and $T 1$ attitudes favorable to deviance (We do not have the measure of T2 attitudes favorable to deviance because data for this measure were not available during the second follow-up survey (1992)). Data for the measures of T1 low self-control and $\mathrm{T} 1$ attitudes favorable to deviance came from the first follow-up survey of NELS (1990) and data for the measure of T2 low self-control came from the second followup survey of NELS (1992).

Since the NELS data do not contain a direct measure of self-control, we relied on teacher ratings of student effort to gauge these indicators. It is noteworthy that our measures parallel the measure adopted by Felson and Staff [66] in their research on the association between academic performance and delinquency. In their study, Felson and Staff [66] defended their decision to measure low self-control via teacher ratings of student effort by pointing out that their variable reflects a student's effort in school and that effort is a function of both attitudes and the ability to regulate behavior. Felson and Staff also claimed that teacher ratings of effort is preferred over self-ratings because teachers are better able to make social comparisons and less likely to have biased judgments. The measure of self-control employed by Felson and Staff also demonstrated high reliability (Cronbach's alpha > $0.80)$.

Following Felson and Staff's [66] rationale, we utilized teacher assessments of student ability to defer gratification, diligence, tenacity, and persistence to indirectly gauge the concept of low self-control. More specifically, our measures of self-control were based on five items that asked teachers to indicate how often the student (1) does his/her homework,
(2) is absent, (3) is tardy, (4) is attentive in class, and (5) is disruptive in class. The response options for the above items included "never," "rarely," "some of the time," "most of the time," and "all of the time." The responses on items one and four were then recoded so that higher scores on the scales indicate lower student's effort or lower levels of selfcontrol. The Cronbach's alpha for the T1 low self-control scale is 0.78 and for the T2 low self-control scale is 0.77 . Table 1 displays the descriptive statistics for these scales (We readily acknowledge that this measure of self-control is not typical of those that appear in the literature such as the frequently used Grasmick scale, and we recognize that in confining selfrestraint to the narrow context of the school the measure is not optimal. In defense of our measure, however, we offer the following: (1) we follow Felson and Staff [66] who used these items to measure self-control, (2) it is all we really have to measure self-control, (3) all of the items do load on a single latent factor in a confirmatory factor analysis, (4) while there are likely several causes of their behavior, we would assert that those students who fail to do homework, are frequently absent or tardy, and who disrupt class will be those on average who find it difficult to control their immediate impulses and are easily attracted by short-term benefits. As with any use of secondary data, the NELS data has some advantages and some disadvantages. We believe that our measure of selfcontrol is not perfect but reasonable).

For the scale of T1 attitudes favorable to deviance, we employed 18 items that asked students to indicate whether they feel it is ok to (1) be late for school, (2) cut a couple of classes, (3) skip school a whole day, (4) cheat on tests, (5) copy someone's homework, (6) get into fights, (7) belong in gangs, (8) make racist remarks, (9) make sexist remarks, (10) steal belongings from school, (11) destroy school property, (12) smoke on school ground, (13) drink alcohol at school, (14) use drugs at school, (15) bring weapons to school, (16) abuse teachers, (17) talk back to teachers, and (18) disobey school rules. The response options for the above items were "often," "sometimes," "rarely," and "never," and these responses were recoded so that higher scores on this scale reflect greater attitudes favorable to deviance. The Cronbach's alpha for the $T 1$ attitudes favorable to deviance scale is 0.87 and the descriptive statistics for this measure is provided in Table 1.

Our family domain consists of three measures, T1 close communication with parents, T2 close communication with parents, and $T 1$ poor supervision/discipline (While Hirschi's concept of "parental attachment" encompasses three key 
dimensions-affective relations, close communication, and parental supervision-the NELS data do not contain a measure of affective relations). T1 close communication with parents and T1 poor supervision/discipline were measured during the first follow-up survey of NELS (1990) while T2 close communication with parents was measured during the second follow-up survey of NELS (1992). We employed six items from the first and second follow-up surveys to construct the scales of close communication with parents. Students were asked how often they discuss the following subjects and activities with their parents: (1) school courses; (2) school activities; (3) things studied in class; (4) course grades; (5) preparation for ACT/SAT; and (6) going to college. The response options for the above items included "never," "sometimes," and "often," and higher scores on these scales reflect close relationships with parents. The Cronbach's alpha for the T1 close communication with parents measure is 0.80 and that for the T2 close communication with parents measure is 0.84 . The descriptive statistics for these measures are listed in Table 1.

Seven items from the first follow-up survey of NELS (1990) were utilized to construct the T1 poor supervision/discipline variable (We do not have the measure of T2 poor supervision/discipline because data for this measure were not available during the second follow-up survey (1992)). Students were asked to indicate how often their parents (1) check their homework, (2) help them with their homework, (3) grant special privileges for good grades, (4) limit privileges for poor grades, (5) require house chores, (6) limit TV watching or video games, and (7) limit time spent with friends. The response options for the above items were "often," "sometimes," "rarely," and "never," and higher scores on the scale reflect poorer parental supervision and discipline. The Cronbach's alpha for the T1 poor supervision/discipline variable is 0.72 and Table 1 contains the descriptive statistics for this measure.

Our school domain includes seven measures with four variables derived from the first follow-up survey of NELS (T1 negative treatment by teacher, T1 negative attachment to school, T1 low educational goals, and T1 homework time) (We do not have the measure of T2 negative treatment by teacher because data for this measure were not available during the second follow-up survey (1992)) and three variables derived from the second follow-up survey of NELS (T2 negative attachment to school, T2 low educational goals, and T2 homework time). To gauge negative treatment by a teacher, we relied on student responses to the statement, "In class, I often feel put down by teachers." This item was measured on a four-point scale-strongly agree, agree, disagree, and strongly disagree-and the responses were then recoded so that higher scores on this item signifies that the student experienced negative treatment by his/her teachers. The descriptive statistics for this item are shown in Table 1.

To construct the measures of T1 negative attachment to school and T2 negative attachment to school, we employed two items from the first and second follow-up surveys (1990 and 1992). Students were asked to indicate whether they "strongly agree," "agree," "disagree," or 'strongly disagree" to the following statements: (1) the teaching is good at school; and (2) teachers are interested in students. Higher scores on these scales reflect weak attachment to school. The Cronbach's alpha for the T1 negative attachment to school variable is 0.72 and 0.75 for the T2 negative attachment to school. The descriptive statistics for these measures are displayed in Table 1 .

The measures of T1 low educational goals and T2 low educational goals were based on one item from the first and second follow-up surveys that asked students to report how far in school they think they will get. The response options for this item included "less than high school graduation," "high school graduation only," "less than 2 years trade school," "more than 2 years trade school," "less than 2 years of college," "2 or more years of college," "finish college," "master degree," and "Ph.D. or M.D." The responses were recoded so that higher scores reflect lower educational aspirations or goals. The descriptive statistics for the above measures are shown in Table 1.

To measure T1 homework time and T2 homework time, we employed two items from the first and second follow-up surveys that asked students to report the amount of time they spent weekly on homework in school and out of school. The response options for these two items ranged from "0" (none) to "7" (over than 15 hours). The responses were combined and higher scores on these variables represent greater amount of time a student spent weekly on homework. Table 1 contains the descriptive statistics for these two variables.

Lastly, our peers domain encompasses two measures, $T 1$ conventional peers and T2 conventional peers (Since the NELS data do not contain a direct measure of delinquent peers, we included the measure of conventional peers for the peers domain. We recognize that this measure is less than ideal but we would like to note that the same measure was employed in prior research to represent Akers's association with peers (see [67])). The measures of $T 1$ and $T 2$ conventional peers were based on five items surveyed during the first and second follow-up study (1990 and 1992). Students were asked to indicate how important the following activities are to their friends: (1) to study; (2) to get good grades; (3) to finish high school; (4) to continue education past high school; and (5) to do community work/volunteer. The response options for these five items were "not important," "somewhat important," and "very important" and higher scores on these scales indicate that a student has more conventional friends. The Cronbach's alpha for $T 1$ and $T 2$ conventional peers is 0.77 . Their descriptive statistics are also displayed in Table 1.

5.2.3. Control Variables. A number of demographic variables were included as control variables (The demographic variables and a measure of criminal victimization from the first follow-up survey of NELS (T1) were utilized as control variables). Specifically, gender, race, parent education, family socioeconomic, school type, and school area were included as controls in the analyses. Gender was coded as a dichotomous variable with $1=$ male and $0=$ female. African American and White were also coded as dichotomous variables with $1=$ African American and $0=$ other race and $1=$ white and $0=$ other race, respectively. The response categories for 
the variable, parent education, were $1=$ less than high school, $2=$ high school grad/GED, $3=$ some college, $4=$ bachelor degree, $5=$ master degree or equivalent, and $6=$ Ph.D./M.D./other. Family SES quartile represents the socioeconomic quartile that a family belongs to with $1=$ low SES quartile, $2=$ moderate SES quartile, and $3=$ high SES quartile. School type was coded as dichotomous variables with $1=$ public school and $0=$ private school and the response categories for the school area variable included $1=$ urban, $2=$ suburban, and $3=$ rural. An additional control variable, measured at Time 1, was whether or not the subject reported being criminally victimized at school (T1 victimization). For this measure, we utilized two items drawn from the first follow-up survey (1990). Students were asked, since the start of the school semester, whether they have experienced any of the following activities: (1) had something been stolen from them and (2) someone threatened to hurt them. The above measures of criminal victimization were combined and recoded into dichotomous variables with $1=$ the student experienced at least one of the above activities and $0=$ the student did not experience any of the above activities. The descriptive statistics for all of the control variables are listed in Table 1.

5.3. Analytic Strategy. Four separate analyses are conducted for the current study. The first analysis examines the contemporaneous effects of the life domain variables on substance use (Hypothesis 1). More specifically, the first analysis contains two models and, in the first model, the dependent variable, $\mathrm{Tl}$ drank alcohol, is regressed on the $\mathrm{T} 1$ life domain variables while controlling for prior substance use (TO prior smoking cigarettes), gender, race, parent education, family SES quartile, school type, school area, and victimization. Similarly, in the second model, the dependent variable, $T 1$ used marijuana, is regressed on the T1 life domain variables while controlling for prior substance use, gender, race, parent education, family SES quartile, school type, school area, and victimization. Further, given that the dependent variables in the first analysis are dichotomous variables, logistic regression is employed.

The second analysis determines the lagged (delayed) effects of the life domain variables on substance use (Hypothesis 2). Similar to the first analysis, the second analysis encompasses two models, with the dependent variable, T2 drank alcohol, is regressed on the T1 life domain variables in the first model and the dependent variable, T2 used marijuana, is regressed on the T1 life domain variables in the second model. Additionally, both models control for prior substance use (T0 prior smoking cigarettes, T1 drank alcohol, and T1 used marijuana), gender, race, parent education, family SES quartile, school type, school district, and victimization experience. Logistic regression is also applied in the second analysis.

The third analysis examines the contemporaneous effects of the life domain variables on one another (Hypothesis 3 ). In this analysis, each of the T1 life domain measures is regressed on the other T1 life domain measures while controlling for prior substance use (T0 prior smoking cigarettes) and control variables. For example, in the first model, the variable, $T 1$ low self-control, is regressed on $\mathrm{Tl}$ attitudes favorable to deviance, T1 close communication with parents, T1 poor supervision/discipline, T1 negative treatment by teacher, T1 negative attachment to school, T1 low educational goals, T1 homework time, and T1 conventional peers while controlling for T0 prior smoking cigarettes, gender, race, parent education, family SES quartile, school type, school district, and victimization. Furthermore, given a total of nine T1 life domain variables and since all of the dependent variables are continuous variables, ordinary least-squared regression is employed.

Finally, the fourth analysis examines the lagged effects of the life domain variables on themselves (Hypothesis 4) and on one another (Hypothesis 5). In this analysis, each of the T1 life domain measures is regressed on each of the T2 life domain measures while controlling for prior substance use (T1 drank alcohol and T1 used marijuana and T0 prior smoking cigarettes) and control variables. Since there are a total of six T2 life domain variables, the fourth analysis contains six models and given that all of the dependent variables are continuous variables, ordinary least-squared regression is employed.

\section{Results}

The analyses begin with the examination of the contemporaneous effects of the life domain variables on adolescent substance use. In particular, to test Hypothesis 1 (T1 life domain variables are significantly related to $\mathrm{T} 1$ drinking and drug use), we regressed $\mathrm{T} 1$ drank alcohol and $\mathrm{T} 1$ used marijuana on the T1 life domain variables (T1 low self-control, T1 attitudes favorable to deviance, T1 close communication with parents, $T 1$ poor supervision/discipline, T1 negative treatment by teacher, T1 negative attachment to school, T1 low educational goals, T1 homework time, and $T 1$ conventional peers) while controlling for prior smoking, gender, race, parent education, family SES quartile, school type, school area, and victimization. The results for Hypothesis 1 are reported in the first two columns of Table 2 (i.e., Models 1 and 2 of Table 2).

According to the results from Table 2, not all of the T1 life domain variables were significantly related to students consuming alcohol or using marijuana in the last 30 days. In particular, all of the variables in the self domain ( $T 1$ low self-control and T1 attitudes favorable to deviance) were significant predictors of students drinking alcohol and using marijuana at $\mathrm{T} 1$ but only one variable in the family and peers domains (T1 poor supervision/discipline and T1 conventional peers, respectively) was a significant predictor of the above activities (Models 1 and 2 of Table 2). On the other hand, none of the four variables in the school domain (T1 negative treatment by teacher, T1 negative attachment to school, T1 low educational goals, and T1 homework time) exhibited a significant association with the likelihood of students drinking alcohol or using marijuana (Models 1 and 2 of Table 2).

Additionally, among the significant life domain variables, T1 low self-control exhibited the greatest effect on the likelihood of students consuming alcohol or using marijuana while T1 poor supervision/discipline displayed the weakest effects on 
TABLE 2: Logistic regressions of alcohol consumption and marijuana usage on Time 1 life domain variables (contemporaneous and lagged effects) ${ }^{\mathrm{a}}$.

\begin{tabular}{|c|c|c|c|c|c|c|}
\hline & $\begin{array}{c}\text { Model } 1 \\
\text { T1 drank alcohol } \\
(N=7190)\end{array}$ & $\begin{array}{c}\text { Model } 2 \\
\text { T1 used } \\
\text { marijuana } \\
(N=7193)\end{array}$ & $\begin{array}{c}\text { Model } 3 \\
\text { T2 drank } \\
\text { alcohol } \\
(N=6112)\end{array}$ & $\begin{array}{c}\text { Model } 4 \\
\text { T2 used } \\
\text { marijuana } \\
(N=5852)\end{array}$ & $\begin{array}{c}(\mathrm{T} 1-\mathrm{T} 2)^{\mathrm{b}} \\
\text { Drank alcohol }\end{array}$ & $\begin{array}{c}(\mathrm{T} 1-\mathrm{T} 2) \\
\text { Used marijuan }\end{array}$ \\
\hline T1 low self-control & $0.116^{*}(1.123)$ & $0.151^{*}(1.163)$ & $0.091^{*}(1.096)$ & $0.096^{*}(1.101)$ & 0.02 & 0.06 \\
\hline $\mathrm{T} 1$ attitudes favorable to deviance & $0.116^{*}(1.123)$ & $0.107^{*}(1.113)$ & $0.044^{*}(1.045)$ & $0.066^{*}(1.068)$ & 0.07 & 0.04 \\
\hline T1 close communication with parents & $0.010(1.010)$ & $-0.027(0.974)$ & $0.017(1.017)$ & $0.008(1.008)$ & -0.01 & -0.02 \\
\hline $\mathrm{T} 1$ poor supervision/discipline & $0.019^{* *}(1.019)$ & $0.047^{*}(1.048)$ & $0.004(1.004)$ & $0.018(1.018)$ & 0.02 & 0.03 \\
\hline T1 negative treatment by teacher & $0.068(1.070)$ & $0.100(1.106)$ & $0.059(1.061)$ & $\begin{array}{c}0.231^{* * *} \\
(1.260)\end{array}$ & 0.01 & -0.15 \\
\hline T1 negative attachment to school & $0.025(1.025)$ & $-0.029(0.972)$ & $0.040(1.041)$ & $-0.044(0.957)$ & -0.01 & -0.01 \\
\hline T1 low educational goals & $-0.017(0.983)$ & $0.032(1.033)$ & $-0.022(0.978)$ & $-0.002(0.998)$ & 0.00 & 0.02 \\
\hline T1 homework time & $-0.009(0.991)$ & $0.012(1.013)$ & $0.013(1.013)$ & $-0.014(0.986)$ & -0.01 & 0.01 \\
\hline $\mathrm{T} 1$ conventional peers & $-0.074^{*}(0.929)$ & $-0.105^{*}(0.901)$ & $-0.035(0.966)$ & $-0.015(0.985)$ & 0.04 & 0.08 \\
\hline T0 prior smoking cigarettes & $0.491^{*}(1.634)$ & $1.344^{*}(3.834)$ & $0.094(1.099)$ & $-0.163(0.849)$ & - & - \\
\hline T1 drank alcohol & - & - & $1.242^{*}(3.463)$ & $0.955^{*}(2.599)$ & - & - \\
\hline $\mathrm{T} 1$ used marijuana & - & - & $0.662^{* *}(1.939)$ & $1.737^{*}(5.680)$ & - & - \\
\hline $\mathrm{T} 1$ victimization & $0.095(1.099)$ & $0.102(1.107)$ & $0.042(1.042)$ & $-0.006(0.994)$ & - & - \\
\hline Gender & $-0.183^{*}(0.833)$ & $\begin{array}{c}-0.377^{*} \\
(0.686)\end{array}$ & $0.248^{*}(1.281)$ & $0.117(1.124)$ & - & - \\
\hline African American & $-0.509^{*}(0.601)$ & $-0.211(0.810)$ & $-0.464^{*}(.628)$ & $-0.573(0.564)$ & - & - \\
\hline White & $0.294^{*}(1.342)$ & $0.204(1.227)$ & $0.176^{* * *}(1.192)$ & $0.194(1.214)$ & - & - \\
\hline Parent education & $-0.048(0.953)$ & $0.003(1.003)$ & $-0.037(0.963)$ & $0.000(1.000)$ & - & - \\
\hline Family SES quartile & $0.137^{* *}(1.147)$ & $0.159(1.172)$ & $0.107(1.112)$ & $0.144(1.155)$ & - & - \\
\hline School type & $-0.373^{*}(0.689)$ & $0.358(1.430)$ & $\begin{array}{c}-0.464^{*} \\
(0.628)\end{array}$ & $-0.171(1.055)$ & - & - \\
\hline School area & $0.096^{* *}(1.101)$ & $\begin{array}{c}-.171^{* * *} \\
(0.843)\end{array}$ & $-0.015(0.985)$ & $-0.124(0.849)$ & - & - \\
\hline Constant & $-3.950^{*}$ & $-6.945^{*}$ & $-2.251^{*}$ & $-6.020^{*}$ & - & - \\
\hline Model $X^{2}$ & $1228.300^{*}$ & $788.60^{*}$ & $691.697^{*}$ & $407.964^{*}$ & - & - \\
\hline Pseudo- $R^{2}$ & 0.16 & 0.10 & 0.17 & 0.11 & - & - \\
\hline
\end{tabular}

${ }^{a}$ Note: entries are unstandardized coefficients; odds ratio are in parentheses; ${ }^{b}$ the last two columns display the differences in terms of odds ratio between the contemporaneous and lagged effects of the T1 life domain variables on T1 drank alcohol and T1 used marijuana.

${ }^{*} P<0.001 ;{ }^{* *} P<0.01 ;{ }^{* * *} P<0.05$.

the likelihood of students engaging in these types of substance use. Having low self-control increased the odds of students consuming alcohol by about $12 \%$ and using marijuana by approximately $16 \%$ (Models 1 and 2 of Table 2 ) and the lack of parental supervision and discipline only increased the odds of students consuming alcohol by about $2 \%$ and using marijuana by about $5 \%$. However, the significant effects of the life domain variables on the likelihood of students drinking alcohol and using marijuana were all in the expected direction. For example, having conventional peers decreased the odds of consuming alcohol by about $7 \%$ and using marijuana by $10 \%$ (Models 1 and 2 of Table 2). Similarly, possessing attitudes favorable to deviance increased the odds of consuming alcohol by approximately $12 \%$ and using marijuana by about 11\% (Models 1 and 2 of Table 2).

Pertaining to the control variables, students who reported that they smoked at least one cigarette previously (1988) were significantly more likely to report drinking alcohol and using marijuana at T1 (1990) relative to students who were nonsmokers. In fact, being a previous smoker increased the odds of drinking alcohol at T1 by approximately $63 \%$ and using marijuana at T1 by nearly $283 \%$ (Models 1 and 2 of Table 2). The results from Table 2 also reveal that being a male decreased the odds of consuming alcohol by about $17 \%$ and using marijuana by approximately $31 \%$ (At the zero-order level, males were significantly more likely to drink alcohol and use marijuana at both $\mathrm{T} 1$ and $\mathrm{T} 2$. The prevalence rate for males for T1 drinking alcohol was 0.43 and 0.38 for females, while at time $\mathrm{T} 2$ the respective prevalence rates were 0.56 and 0.46 (both differences are significant at $P<0.001$ ). The prevalence rates for males for T1 marijuana use were 0.08 and 0.06 for females, while the $\mathrm{T} 2$ rates for males and females were 0.12 and 0.08 (both differences significant at $P<0.01$ ). In a bivariate logistic regression analysis males were significantly 
more likely than females to use both substances at both $\mathrm{T} 1$ and $\mathrm{T} 2$. Since the multivariate finding for gender in Table 2 is contrary to these bivariate results and extant empirical evidence we conducted additional analyses and discovered that, relative to female students, male students in our sample were significantly more likely to engage in substance use because they reported higher levels of antisocial beliefs. Accordingly, once antisocial beliefs are controlled for in a series of logistic regression models with only gender and attitudes toward deviance, gender demonstrated a negative association with both drinking and marijuana use indicating a higher risk for males.). Further, relative to students from other racial backgrounds, African American students were significantly less likely to consume alcohol but Caucasian students were more likely to engage in this activity (Model 1 of Table 2). This finding is consistent with recent previous research which shows that compared with Caucasian youth African-American adolescents are more likely to abstain from alcohol use, drink less frequently when they do drink, and are less likely to engage in binge drinking [68-70]. The results from Table 2 also indicate that students attending public schools were less likely to consume alcohol relative to students attending private schools and students attending schools located in rural areas were significantly more likely to consume alcohol relative to students attending schools located in suburban and urban areas (Model 1 of Table 2). Accordingly, Hypothesis 1 appears to receive some support.

To assess the lagged effects of the life domain variables on substance use (Hypothesis 2), we regressed T2 drank alcohol and T2 used marijuana on the T1 life domain variables (T1 low self control, T1 attitudes favorable to deviance, T1 close communication with parents, T1 poor supervision/discipline, T1 negative treatment by teacher, T1 negative attachment to school, T1 low educational goals, T1 homework time, T1 negative attachment to school, T1 low educational goals, T1 homework time and $T 1$ conventional peers) while controlling for T0 prior smoking cigarettes, T1 drank alcohol, T1 used marijuana, gender, race, parent education, family SES quartile, school type, school area, and victimization. The results for this analysis are reported in Table 2 (Models 3 and 4 of Table 2). Since we hypothesized that the effects of the T1 life domain variables on T2 substance use (lagged effects) would be smaller than the effects of the T1 life domain variables on T1 substance use (contemporaneous effects), we compare the results from Models 3 and 4 (lagged effects) on Table 2 with the results from Models 1 and 2 on Table 2 (contemporaneous effects; see the last two columns of Table 2) (The last two columns of Table 2 display the differences in terms of odds ratio between the contemporaneous and lagged effects of the T1 life domain variables on T1 substance use (T1 drank alcohol and T1 used marijuana). A negative value indicates that the lagged effect of the T1 life domain variables on $\mathrm{T} 1$ use is greater than the contemporaneous effect.).

The results from Table 2 appear to provide modest support for Hypothesis 2. Overall, the effects of T1 life domain variables on T2 substance use (lagged effects) were smaller than the effects of $\mathrm{T} 1$ life domain variables on $\mathrm{T} 1$ substance use (contemporaneous effects; see the last two columns of Table 2). For instance, although the odds of students with low levels of self-control consuming alcohol at $\mathrm{T} 1$ (contemporaneous effect) were increased by about $12 \%$, the odds of students with low self-control drinking alcohol at T2 (lagged effect) were increased by only $10 \%$ with a one unit change in the self-control scale (i.e., a decrease in the odds by approximately $2 \%$ from T1 to T2; see the fifth column on Table 2). Similarly, while the odds of students with low levels of self-control using marijuana at $\mathrm{T} 1$ (contemporaneous effect) increased by $16 \%$ with a one unit increase in selfcontrol, the odds of students with low levels of self-control using marijuana at T2 (lagged effect) increased by just $10 \%$ (i.e., a decrease in the odds by about $6 \%$ from $\mathrm{T} 1$ to $\mathrm{T} 2$; see the last column of Table 2). Likewise, although the odds of consuming alcohol and using marijuana at T1 (contemporaneous effects) increased by $12 \%$ and $11 \%$, respectively, for a one unit change in favorable attitudes toward deviance, for the lagged effects these odds increased by $5 \%$ and $7 \%$ at T2 (i.e., a decreased in the odds by approximately $7 \%$ for consuming alcohol from $\mathrm{T} 1$ to $\mathrm{T} 2$ and a decrease in the odds by about $4 \%$ for using marijuana from $\mathrm{T} 1$ to $\mathrm{T} 2$; see the last two columns of Table 2).

However, Table 2 also reveals several findings incongruous with the theory. In particular, whereas negative treatment by a teacher did not have a significant impact on students using marijuana at $\mathrm{T} 1$ (contemporaneous effect), negative treatment by a teacher significantly increased the odds of students using marijuana at T2 (lagged effect; compare Model 2 with Model 4 of Table 2). Specifically, although the odds of students who were mistreated by a teacher using marijuana at $\mathrm{T} 1$ (contemporaneous effects) increased by $11 \%$ for a one unit change in negative treatment by a teacher, the odds of students who were mistreated by a teacher using marijuana at T2 (lagged effects) increased by $26 \%$ (i.e., an increase in the odds by approximately $15 \%$ for using marijuana from T1 to T2; see the last column of Table 2). The results from Table 2 also indicate that while the odds of students with weak attachment to school consuming alcohol at $\mathrm{T} 1$ (contemporaneous effect) increased by $3 \%$ with a one unit increase in attachment to school, the odds of students with weak attachment to school consuming alcohol at T2 (lagged effect) increased by $4 \%$ (i.e., an increase in the odds by $1 \%$ from T1 to T2; see the fifth column of Table 2).

With regard to the control variables, the results from Table 2 indicate that consuming alcohol and using marijuana previously significantly increased the odds of subsequent alcohol consumption as well as marijuana usage. Specifically, students who reported that they consumed alcohol at T1 were substantially more likely ( $246 \%$ more) to report engaging in underage drinking at T2 relative to students who did not consume alcohol at T1 (Model 3 of Table 2). Similarly, students who engaged in underage drinking at $\mathrm{T} 1$ were almost twice $(160 \%)$ as likely to report using marijuana at T2 relative to students who did not consume alcohol at T1 (Model 4 of Table 2). Likewise, students who reported that they used marijuana at $\mathrm{T} 1$ were significantly more likely to consume alcohol (by about 94\%) or use marijuana (over 468\%) at T2 relative to students who did not use marijuana at T1 (Models 3 and 4 of Table 2). Finally, students with a prior history of 
smoking cigarettes were significantly more likely to drink alcohol and use marijuana at Time 1 but this relationship declines to insignificance with the Time 2 measures.

The results on Table 2 also reveal that relative to female students, male students were significantly more likely to consume alcohol (at T2), and, relative to students attending private schools, students attending public schools were less likely to drink alcohol at both time periods. Also, African American students were significantly less likely to engage in underage drinking at $\mathrm{T} 1$ and $\mathrm{T} 2$ than those of other races, while compared with students of other races Caucasian students were significantly more likely to report drinking alcohol at both times. Finally, the results on Table 2 also indicate that relative to students from urban and suburban areas, students from rural areas were significantly less likely to report drinking alcohol and using marijuana at T1 (Models 1 and 2 of Table 2).

To examine the contemporaneous effects of the life domain variables on one another (Hypothesis 3), we regressed each of the T1 life domain variables (T1 low self control, T1 attitudes favorable to deviance, T1 close communication with parents, T1 poor supervision/discipline, T1 negative treatment by teacher, t1 negative attachment to school, T1 low educational goals, T1 homework time, and T1 conventional peers) on the other $\mathrm{T} 1$ life domain variables while controlling for prior substance use (T0 prior smoking cigarettes), gender, race, parent education, family SES quartile, school type, school area, and victimization. These ordinary least-squared regression results are shown in Table 3.

Contrary to the theory's prediction that each of the T1 life domain variables will be significantly related to each of the other T1 life domain variables, the results from Table 3 reveal that not all of the life domain variables are related to one another. The results are, however, rather impressive with most of the estimated OLS coefficients statistically significant. Two of the life domain variables ( $\mathrm{T} 1$ attitudes favorable to deviance and $T 1$ close communication with parents) were significantly related to the other eight life domain variables. Another four of the nine life domain variables (T1 low self control, T1 poor supervision/discipline, T1 negative attachment to school, and T1 homework time) were significantly related to seven of the other eight life domain variables, and the last three of the life domain variables ( $T 1$ conventional peers, T1 negative treatment by teachers, and T1 low educational goals) were significantly related to six of the other eight life domain variables.

It is noteworthy that except for the school domain, we also uncovered that the variables within each of the life domains were significantly related to one another. For example, within the self domain, T1 low self control and T1 attitudes favorable to deviance were significantly related to one another. Similarly, within the family domain, $\mathrm{Tl}$ close communication with parents and T1 poor supervision/discipline were significantly associated with each other. Additionally, the significant effects of each of the life domain variables on the other life domain variables were all in the expected direction. For instance, students with low levels of self-control tended to also possess attitudes favorable to deviance and students with attitudes favorable to deviance also tended to demonstrate low selfcontrol. Further, students who were close to their parents were less likely to experience poor parental supervision and discipline and students who received inadequate parental supervision and discipline were also those who did not have a close relationship with their parents.

Within the school domain, none of the variables was significantly related to all of the other four variables ( $T 1$ negative treatment by teacher, $\mathrm{T} 1$ negative attachment to school, T1 low educational goals, and T1 homework time). However, among the significant effects, they were all in the expected direction. That is, students with weak bonds to their schools tended to experience negative treatment by their teachers and students who were mistreated by their teachers also appeared to demonstrate weak bonds to their schools. Similarly, students with weak bonds to their schools tended to spend little time on their homework and students who did not spend a lot of time on their homework also appeared to be those with weak attachment to their schools. The results on Table 3 also indicate that students who spent little time on their homework tended to possess low educational goals and students with low educational goals also appeared to be those who did not spend a lot of time on their homework.

To assess the lagged effects of the life domain variables on themselves and on one another, we regressed each of the $\mathrm{T} 1$ life domain variables ( $\mathrm{T} 1$ low self control, $\mathrm{T} 1$ close communication with parents, T1 negative attachment to school, $T 1$ low educational goals, T1 homework time, T1 conventional peers) on each of the T2 life domain variables (T2 low self control, T2 close communication with parents, T2 negative attachment to school, T2 low educational goals, T2 homework time, T2 conventional peers) (Since we are interested in examining the lagged effects of the life domain on themselves, we only included the same life domain variables measured at T1 and T2. Accordingly, this analysis excluded three T1 variables (T1 attitudes favorable to deviance, T1 poor supervision/discipline, and T1 negative treatment by teacher) because data for these measures were not available during the second follow-up survey (1992)) while controlling for prior substance use (T1 drank alcohol, T1 used marijuana, and T0 prior smoking cigarettes), gender, race, parent education, family SES quartile, school type, school area, and victimization. The ordinary least-squared regression results are shown in Table 4.

Pertaining to Hypothesis 4 (T1 life domain variables are significantly related to the same T2 life domain variables), the results from Table 4 provides support for this hypothesis in that each of the T2 life domain variables was significantly and positively related to its own lagged measure at T1. For example, students with low levels of self-control at T1 also exhibited low levels of self-control at T2 (Model 1 of Table 4). Similarly, students with low educational goals at $\mathrm{T} 1$ continued to possess low educational goals at $\mathrm{T} 2$ and students with conventional friends at $\mathrm{T} 1$ continued to have conventional friends at T2 (Models 4 and 6 of Table 4). With regard to Hypothesis 5 (the lagged effects of the life domain variables are smaller than their contemporaneous effects), we compare the results from Table 3 with the results from Table 4 (The right side of each column in Table 4 displays the differences in terms of the regression coefficients between the contemporaneous (results from Table 3 ) and lagged effect (results from Table 4) 


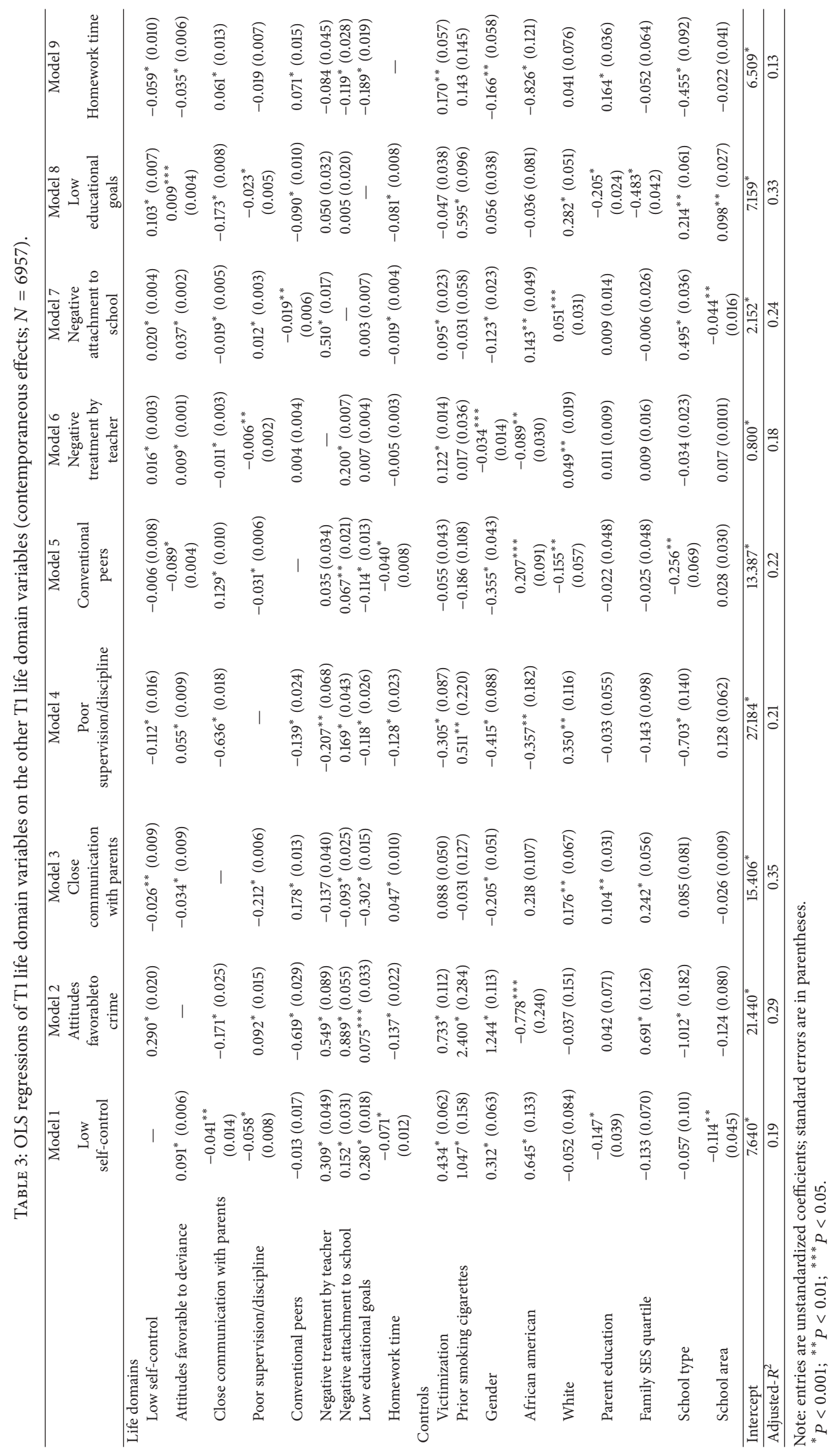




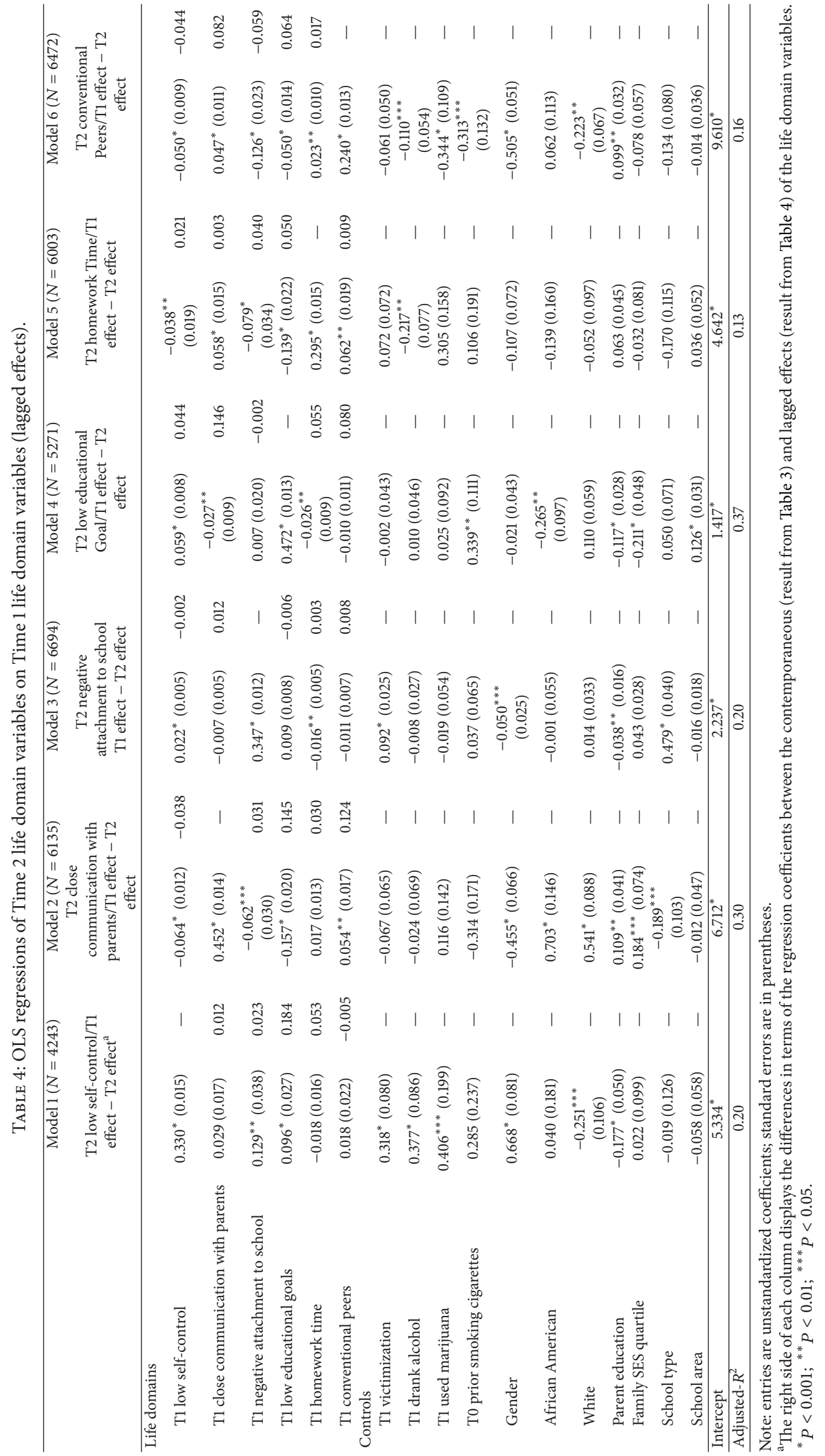


of the life domain variables. A negative value indicates that the lagged effect of the life domain variables is greater than the contemporaneous effect). We uncovered several notable findings. First, we found that several of the life domain variables that were significantly related to one another at $\mathrm{T} 1$ failed to exhibit a significant association with each other at Time 2. For instance, whereas T1 close communication with parents was significantly related to $T 1$ self control and $T 1$ negative attachment to school, T1 close communication with parents displayed no significant impact on T2 self control and T2 negative attachment to school (compare Models 1 and 7 on Table 3 with Models 1 and 3 on Table 4). Similarly, although $T 1$ homework time was significantly associated with T1 self control and T1 close communication with parents, T1 homework time exhibited a null relationship with T2 self control and T2 close communication with parents (compare Models 1 and 3 on Table 3 with Models 1 and 2 on Table 4).

Second, in comparing the magnitude of the effects among the life domain variables, we found that overall the lagged effects of the life domain variables on one another were smaller relative to their contemporaneous effects. For example, while the magnitude of the contemporaneous effect between T1 low educational goals and T1 low self control was 0.280 , the magnitude of the lagged effect between these two variables (T1 low educational goals and T2 low self control) decreased to 0.096 (compare Model 1 on Table 3 with Model 1 on Table 4). A difference of coefficients test (The formula we used to test for the difference between two OLS coefficients was

$$
z=\frac{\left(b_{1}-b_{2}\right)}{\sqrt{\operatorname{se}\left(b_{1}\right)+\operatorname{se}\left(b_{2}\right)}}
$$

(see [71])) indicated that the two coefficients are different at $P<0.001$. Similarly, although the magnitude of the contemporaneous effect between T1 low educational goals and $T 1$ close communication with parents was -0.302 , the magnitude of the lagged effects (T1 low educational goals and T2 close communication with parents) decreased to -0.157 (compare Model 3 on Table 3 with Model 2 on Table 4: coefficients significantly different at $P<0.001$ ).

However, the larger magnitude of the contemporaneous effects over the lagged was not always true as there were instances, where the lagged effects among the life domain variables were greater than their contemporaneous effects. For example, although the magnitude of the effect between T1 low self control and T1 close communication with parents was -0.026 (contemporaneous effect), the magnitude of their lagged effect ( $T 1$ low self control and T2 close communication with parents) increased to -0.064 (compare Model 3 on Table 3 with Model 2 on Table 4; coefficients significantly different at $P<0.01$ ). Third, we discovered one life domain variable that did not demonstrate a significant contemporaneous effect but exhibited a significant lagged effect. More specifically, although $T 1$ low self control and T1 conventional peers were not related to one another $(b=-0.006, P>0.05)$, T1 low self control was significantly related to T2 conventional peers $(b=-0.050, P<0.001$; compare Model 5 of Table 3 with Model 6 of Table 4: coefficients significantly different at $P<0.001)$.

Lastly, we found prior substance use (T1 drank alcohol, T1 used marijuana) was significantly related to some of the six T2 life domain variables. For example, both $T 1$ drinking and marijuana use were significantly related to T2 low self control, T0 smoking cigarettes was related to T2 low educational goals, $\mathrm{T} 1$ drinking alcohol was related to T2 Homework Time, and all three indicators of substance use were related to $T 2$ conventional peers.

\section{Discussion and Conclusion}

Robert Agnew is best known for his general strain theory (GST; [72-74]) and for his efforts at revitalizing traditional strain theory [75, 76]. However, in 2005, Agnew moved beyond the strain theoretical framework and crafted an integrated general theory of criminal offending that is not just premised on GST but on the most important known correlates of crime. It is noteworthy that Agnew's general theory is not a new theory per se. Agnew's theory is essentially a cobbling together of concepts from other criminological theories (see e.g., $[5,16,17,23,26,38,77,78]$ ) and as some scholars may argue, really offers nothing new to the study of crime and criminals. Whatever else may be said about Agnew's general theory, much to his credit, Agnew attempted to organize extant theories and research into an integrated whole as well as deduce some specific hypotheses or empirical implications which allow an empirical test of his perspective. In particular, recognizing the shortcomings associated with integrated general theories developed in the 1990s and early 2000s including the tendency of these theories to focus on a central causal variable while excluding other major causes of crime, the failure of them to specify exactly how the causes interact with one another in affecting crime and the timing of causal effects, and the lack of testing and empirical evidence given these theories' overly complexity, Agnew sought to develop a theoretical perspective that is not only reasonably complete but also not too so complex as to overwhelm criminologists and researchers (for further discussion on this topic, see [2, Chapter 1]).

In this paper, we tested parts of Agnew's theory on a sample of adolescents. Agnew is very clear as to his theory's empirical implications. He argues that, if the theory is true, then each one of the life domains should be related to crime, delinquency, and illegal substance use (although since the causal process is age graded, some will be more strongly related at different points in the life course), the life domains should have largely contemporaneous effects on one another and on antisocial conduct, and each life domain should have a large lagged (delayed) effect on itself. Employing measures of the life domains of self, family, school, and peers, we examined the contemporaneous and lagged effects of these life domain variables on the likelihood of engaging in underage drinking and using marijuana as well as the contemporaneous and lagged effects of the life domain variables on themselves and on one another. Overall, we found a very mixed bag of results, perhaps not surprisingly given the ambitiousness of the theory. 
Pertaining to our first hypothesis that examined the contemporaneous effects of the life domains on substance use (i.e., T1 life domain variables are significantly related to $\mathrm{T} 1$ alcohol and marijuana use), we found some support for this hypothesis in that all of the variables in the self and the peers domains and one variable in the family domain were significantly related to the likelihood of drinking alcohol and using marijuana (Models 1 and 2 of Table 2). We also found that among the significant life domain predictors, the variables within the self domain demonstrated the greatest effects on the likelihood of students consuming alcohol and using marijuana. It is noteworthy that this finding is congruent with Agnew's contention that during the adolescent years, relative to the other life domains, the self domain would exhibit large direct effects on antisocial behavior (for a more detailed discussion on this topic, see [2, Chapter $4])$. We also uncovered that none of the variables in the school domain had an impact on the likelihood of consuming alcohol or using marijuana at T1 (Models 1 and 2 of Table 2). It is plausible that the effects of the school domain variables on substance use are conditioned by the levels of the other life domains. According to Agnew [2], although "The core proposition of the general theory is that the five life domains cause individuals to engage in crime ... that is not always the case" (p. 110) because the effect of each life domain on crime may be influenced by the individual's standing on the other life domains. Accordingly, while an adolescent may have low educational goals, s/he will not engage in delinquency and problem behaviors like drinking and using marijuana if $\mathrm{s} /$ he possesses high levels of self-control, is strongly attached to his/her parents, or socializes with conventional peers. Since we did not examine interaction effects among the life domains and substance use in our current study and given that one of the core propositions maintained by Agnew's theory is that the life domains interact with one another in affecting crime, we strongly encourage future research to explore this aspect of Agnew's theory.

With regard to our second hypothesis that assessed the lagged effects of the life domain variables on substance use (i.e., the effects of $\mathrm{T} 1$ life domain variables on $\mathrm{T} 2$ drinking and marijuana use are smaller relative to the effects of $\mathrm{T} 1$ life domain variables on T1 use), we also found support for this hypothesis in that, overall, the life domain variables exhibited largely contemporaneous effects on the likelihood of consuming alcohol and using marijuana. However, we also uncovered several instances, where the lagged effects of the life domain variables were greater than their contemporaneous effects (The last two columns of Table 2). Notably, we found that while the measure of one life domain variable, $T 1$ negative treatment by teacher, was not related to the outcome variable (T1 used marijuana) at Time 1, it was significantly associated with the outcome variable at Time 2 (T2 used marijuana; compare Models 2 and 4 of Table 2).

Accordingly, it appears that an adolescent's past school experiences could affect his/her likelihood of engaging in drinking alcohol and using marijuana. Notwithstanding the above contradictory findings to Agnew's general theory, given that we did not control for the T2 life domain variables in our analysis, we encourage researchers to include both contemporaneous and lagged measures of the life domains in future tests of Agnew's general theory. Additionally, it is probable that the observed lagged effects of $T 1$ negative treatment by teacher on using marijuana in our study may be due to unmeasured factors or influences. While we attempted to account for some of the more immediate influences in our analyses (i.e., sex, race, ethnicity, and family SES; see [2, Chapter 8]), we were not able to examine the impact of other influences (e.g., changes in school curriculum, policies, and disciplinary practices, the amount of time teachers spent on academic tasks, the frequency of student performance evaluations, etc.) as well as larger social and cultural forces on the life domains as suggested by Agnew [2, Chapter $8]$. Hence, we also urge future research to undertake the challenge of uncovering how larger social and cultural forces work through the life domains to affect crime.

With regard to our third hypothesis that investigated the contemporaneous effects of the life domain variables on one another (i.e., T1 life domain variables are significantly related to the other T1 life domain variables), overall, we found support for this hypothesis in that two of the T1 life domain variables ( $T 1$ attitudes favorable to deviance and $T 1$ close communication with parents) were significantly related to all other eight variables and the remaining variables were significantly related to at least six other $\mathrm{T} 1$ life domain variables (Table 3 ). We also uncovered that the variables within each of the life domains were related to one another in the expected direction and this finding appears to corroborate Agnew's supposition that the life domains mutually reinforce one another in affecting crime [2, Chapter 4].

We also found some support for our fourth hypothesis (T1 life domain variables are significantly related to the same T2 life domain variables) and our last hypothesis (the lagged effects of the life domain variables are smaller than their contemporaneous effects) in that each of the life domain variables measured at $\mathrm{T} 1$ was significantly related to the same variable measured at T2 (Table 3) as well as, overall, the lagged effects of the life domain variables on one another were smaller relative to their contemporaneous effects (Compare Table 3 with Table 4.). However, we also noted several findings that were inconsistent with Agnew's propositions. First, we found several instances in which the lagged effects of the life domain variables on one another were greater than their contemporaneous effects and a few, where the life domain variable did not demonstrate a significant contemporaneous effect on another life domain variable but did exhibit a significant lagged effect. We believe that the above findings validate the complexity of Agnew's general theory that suggests direct, indirect, interaction, as well as reciprocal effects among the life domains and crime. We recommend that these effects be explored in greater detail in subsequent research with more suitable measures of the domains.

Further, we would be remiss if we do not acknowledge that the above findings may also be due to the limitations associated with several of our life domain measures. Specifically, we did not have a direct measure of low self-control and peer delinquency and our family domain lacked the measure of attachment to parents. Our study also excluded 
several key variables within the life domains as stipulated by Agnew. For instance, in the self domain, Agnew posits that low self-control and the super trait of "irritability" constitute the main factors that directly weaken the constraints against and strengthen the motivations for crime but the NELS data do not contain a measure for the irritability variable. Hence, we encourage future research to include more appropriate variables as well as expand the number of variables within each life domain in their tests of Agnew's theory.

While, overall, our findings are supportive of Agnew's general theory of crime and delinquency, we also uncovered and presented several notable puzzles for future research to work on and address. Our findings also underscore the complex nature of Agnew's theoretical perspective that warrants the examination of direct, indirect, interaction, and reciprocal effects among the life domains and crime and the incorporation of outside factors and larger social and cultural forces into future tests of the general theory. While clearly not a homage to parsimony, Agnew's general theory does hold promise of uniting diverse theoretical perspectives into an organized framework for understanding crime. Therefore, notwithstanding the challenging tasks proposed by our study, we hope our efforts will stimulate further research and attention to this potentially important contemporary theoretical perspective.

\section{Conflict of Interests}

The authors declare that there is no conflict of interests regarding the publication of this paper.

\section{References}

[1] T. J. Bernard and J. B. Snipes, "Theoretical integration in criminology. Crime and Justice," An Annual Review of Research, vol. 20, pp. 301-348, 1996.

[2] R. Agnew, Why Do Criminals Offend? A General Theory of Crime and Delinquency, Roxbury, Los Angeles, Calif, USA, 2005.

[3] F. T. Ngo, R. Paternoster, F. T. Cullen, and D. L. Mackenzie, "Life domains and crime: a test of Agnew's general theory of crime and delinquency," Journal of Criminal Justice, vol. 39, no. 4, pp. 302-311, 2011.

[4] F. T. Cullen and R. Agnew, Criminological Theory: Past to Present, Roxbury, Los Angeles, Calif, USA, 2006.

[5] M. Gottfredson and T. Hirschi, A General Theory of Crime, Stanford University Press, Palo Alto, Calif, USA, 1990.

[6] A. Caspi, T. E. Moffitt, P. A. Silva, M. Stouthamer-Loeber, R. F. Krueger, and P. S. Schmutte, "Are some people more crime prone? Replications of the personality-crime relationship across countries, genders, races, and methods," Criminology, vol. 32, no. 2, pp. 163-196, 1994.

[7] C. R. Colder and E. Stice, "A longitudinal study of the interactive effects of impulsivity and anger on adolescent problem behavior," Journal of Youth and Adolescence, vol. 27, no. 3, pp. 255-274, 1998.

[8] H. G. Grasmick, C. R. Tittle, R. J. Bursik Jr., and B. J. Arneklev, "Testing the core empirical implications of Gottfredson and Hirschi's general theory of crime," Journal of Research in Crime and Delinquency, vol. 30, no. 1, pp. 5-29, 1993.
[9] J. D. Miller and D. Lynam, "Structural models of personality and their relation to antisocial behavior: a meta-analytic review," Criminology, vol. 39, no. 4, pp. 765-798, 2001.

[10] T. C. Pratt and F. T. Cullen, "The empirical status of Gottfredson and Hirschi's general theory of crime: a meta-analysis," Criminology, vol. 38, no. 3, pp. 931-964, 2000.

[11] B. R. E. Wright, A. Caspi, T. E. Moffitt, and P. A. Silva, "Low self-control, social bonds, and crime: social causation, social selection, or both?" Criminology, vol. 37, no. 3, pp. 479-514, 1999.

[12] K. L. Kempf, "The empirical status of social control theory," in New Directions in Criminological Theory, F. Adler and W. S. Laufer, Eds., vol. 4, pp. 143-185, Transaction, New Brunswick, NJ, USA, 1993.

[13] M. D. Krohn and J. L. Massey, "Social control and delinquent behavior: an examination of the elements of the social bond," Sociological Quarterly, vol. 21, no. 4, pp. 529-543, 1980.

[14] M. D. Wiatrowski, D. B. Griswold, and M. K. Roberts, "Social control theory and delinquency," American Sociological Review, vol. 46, no. 5, pp. 525-541, 1981.

[15] R. Agnew, C. Rebellon, and S. Thaxton, "A general strain theory approach to families," in Families, Crime and Criminal Justice, G. L. Fox and M. L. Benson, Eds., JAI Press, New York, NY, USA, 2000.

[16] G. R. Patterson, J. B. Reid, and T. J. Dishion, Antisocial Boys, Castalia, Eugene, Ore, USA, 1992.

[17] R. L. Akers, Deviant Behavior: A Social Learning Approach, Wadsworth, Belmont, Calif, USA, 1985.

[18] E. Anderson, Code of the Street, W. W. Norton, New York, NY, USA, 1999.

[19] G. Canada, Fist Stick Knife Gun, Beacon Press, Boston, Mass, USA, 1995.

[20] J. Miller, One of the Guys: Girls, Gangs, and Gender, Oxford, New York, NY, USA, 2001.

[21] J. Horney, D. W. Osgood, and I. H. Marshall, "Criminal careers in the short-term: intra-individual variability in crime and its relation to local life circumstances," American Sociological Review, vol. 60, no. 5, pp. 655-673, 1995.

[22] A. R. Piquero, R. Brame, P. Mazerolle, and R. Haapanen, "Crime in emerging adulthood," Criminology, vol. 40, no. 1, pp. 137-170, 2002.

[23] R. J. Sampson and J. H. Laub, Crime in the Making: Pathways and Turning Points Through Life, Harvard University Press, Cambridge, Mass, USA, 1993.

[24] J. H. Laub and R. J. Sampson, Shared Beginning, Divergent Lives: Delinquent Boys to Age 70, Harvard University Press, Cambridge, UK, 2003.

[25] R. L. Simons, E. Stewart, L. C. Gordon, R. D. Conger, and G. H. Elder Jr., "A test of life-course explanations for stability and change in antisocial behavior from adolescence to young adulthood," Criminology, vol. 40, no. 2, pp. 401-434, 2002.

[26] R. Agnew, Juvenile Delinquency: Causes and Control, Roxbury, Los Angeles, Calif, USA, 2005.

[27] M. Colvin, Crime \& Coercion, St. Martin’s Press, New York, NY, USA, 2000.

[28] D. C. Gottfredson, Schools and Delinquency, Cambridge University Press, Cambridge, UK, 2001.

[29] J. MacLeod, Ain't No Makin' It, Westview, Boulder, Colo, USA, 1995.

[30] R. Agnew, "Experienced, vicarious, and anticipated strain: an exploratory study on physical victimization and delinquency," Justice Quarterly, vol. 19, no. 4, pp. 602-632, 2002. 
[31] R. L. Akers, Social Learning and Social Structure: A General Theory of Crime and Deviance, Northeastern University Press, Boston, Mass, USA, 1998.

[32] R. H. Aseltine Jr., "A reconsideration of parental and peer influences on adolescent deviance," Journal of Health and Social Behavior, vol. 36, no. 2, pp. 103-121, 1995.

[33] S. A. Cernkovich and P. C. Giordano, "Stability and change in antisocial behavior: the transition from adolescence to early adulthood," Criminology, vol. 39, no. 2, pp. 371-410, 2001.

[34] D. L. Haynie, "Delinquent peers revisited: does network structure matter?" American Journal of Sociology, vol. 106, no. 4, pp. 1013-1057, 2001.

[35] D. L. Haynie, "Friendship networks and delinquency: the relative nature of peer delinquency," Journal of Quantitative Criminology, vol. 18, no. 2, pp. 99-134, 2002.

[36] D. Huizinga, A. W. Weiher, R. Espiritu, and F. Esbensen, "Delinquency and crime: some highlights from the Denver youth survey," in Taking Stock of Delinquency, T. P. Thornberry and M. D. Krohn, Eds., pp. 47-91, Kluwer Academic/Plenum, New York, NY, USA, 2003.

[37] T. P. Thornberry, A. J. Lizotte, M. D. Krohn, C. A. Smith, and P. K. Porter, "Causes and consequences: findings from the Rochester youth development survey," in Taking Stock of Delinquency, T. P. Thornberry and M. D. Krohn, Eds., pp. 11-46, Kluwer Academic/Plenum, New York, NY, USA, 2003.

[38] M. Warr, Companions in Crime, Cambridge, Cambridge, UK, 2002.

[39] A. R. Piquero and G. Pogarsky, "Beyond Stafford and Warr's reconceptualization of deterrence: personal and vicarious experiences, impulsivity, and offending behavior," Journal of Research in Crime and Delinquency, vol. 39, no. 2, pp. 153-186, 2002.

[40] M. C. Stafford and M. Warr, "A reconceptualization of general and specific deterrence," Journal of Research in Crime and Delinquency, vol. 30, no. 2, pp. 123-135, 1993.

[41] D. Eitle and R. J. Turner, "Exposure to community violence and young adult crime: the effects of witnessing violence, traumatic victimization, and other stressful life events," Journal of Research in Crime and Delinquency, vol. 39, no. 2, pp. 214-237, 2002.

[42] J. E. Hawdon, "Daily routines and crime: using routine activities as measures of Hirschi's involvement," Youth and Society, vol. 30, no. 4, pp. 395-415, 1999.

[43] D. W. Osgood, J. K. Wilson, P. M. O’Malley, J. G. Bachman, and L. D. Johnston, "Routine activities and individual deviant behavior," American Sociological Review, vol. 61, no. 4, pp. 635655, 1996.

[44] P. C. Giordano, S. A. Cernkovich, and J. L. Rudolph, "Gender, crime, and desistance: toward a theory of cognitive transformation," American Journal of Sociology, vol. 107, no. 4, pp. 990 1064, 2002.

[45] J. H. Laub and R. J. Sampson, "Understanding desistance from crime," Crime and Justice, vol. 28, pp. 1-70, 2001.

[46] M. Rutter, H. Giller, and A. Hagel, Antisocial Behavior by Young People, Cambridge University Press, Cambridge, UK, 1998.

[47] N. Shover and J. P. Wright, Crimes of Privilege, Oxford University Press, New York, NY, USA, 2001.

[48] M. L. Sullivan, "Getting Paid": Youth Crime and Work in the Inner City, Cornell University Press, New York, NY, USA, 1989.

[49] C. Uggen, "Work as a turning point in the life course of criminals: a duration model of age, employment, and recidivism," American Sociological Review, vol. 65, no. 4, pp. 529-546, 2000.
[50] J. R. Aulette and R. Michalowski, "Fire in hamlet: a case study of a stable-corporate crime," in Political Crime in Contemporary America, K. D. Turnell, Ed., pp. 171-206, Garland, New York, NY, USA, 1993.

[51] R. D. Crutchfield and S. R. Pitchford, "Work and crime: the effects of labor stratification," Social Forces, vol. 76, no. 1, pp. 93118, 1997.

[52] J. P. Wright and F. T. Cullen, "Juvenile involvement in occupational delinquency," Criminology, vol. 38, no. 3, pp. 863-896, 2000.

[53] H. S. Becker, Outsiders: Studies in the Sociology of Deviance, Macmillan, New York, NY, USA, 1963.

[54] E. Lemert, Social Pathology, McGraw-Hill, New York, NY, USA, 1951.

[55] T. E. Moffitt, "Adolescence-limited and life-course-persistent antisocial behavior: a developmental taxonomy," Psychological Review, vol. 100, no. 4, pp. 674-701, 1993.

[56] C. B. Fleming, R. F. Catalano, K. P. Haggerty, and R. D. Abbott, "Relationships between level and change in family, school, and peer factors during two periods of adolescence and problem behavior at age 19," Journal of Youth and Adolescence, vol. 39, no. 6, pp. 670-682, 2010.

[57] P. Logan-Greene, P. S. Nurius, J. R. Herting, C. L. Hooven, E. Walsh, and E. A. Thompson, "Multi-domain risk and protective factor predictors of violent behavior among at-risk youth," Journal of Youth Studies, vol. 14, no. 4, pp. 413-429, 2011.

[58] M. J. Cleveland, M. E. Feinberg, D. E. Bontempo, and M. T. Greenberg, "The role of risk and protective factors in substance use across adolescence," Journal of Adolescent Health, vol. 43, no. 2, pp. 157-164, 2008.

[59] L. Bond, H. Butler, L. Thomas et al., "Social and school connectedness in early secondary school as predictors of late teenage substance use, mental health, and academic outcomes," Journal of Adolescent Health, vol. 40, no. 4, pp. 357-389, 2007.

[60] G. L. Bowen, R. A. Rose, J. D. Powers, and E. J. Glennie, "The joint effects of neighborhoods, schools, peers, and families on changes in the school success of middle school students," Family Relations, vol. 57, no. 4, pp. 504-516, 2008.

[61] M. E. Woolley and A. Grogan-Kaylor, "Protective family factors in the context of neighborhood: promoting positive school outcomes," Family Relations, vol. 55, no. 1, pp. 93-104, 2006.

[62] M. L. Cooper, P. K. Wood, H. K. Orcutt, and A. Albino, "Personality and the predisposition to engage in risky or problem behaviors during adolescence," Journal of Personality and Social Psychology, vol. 84, no. 2, pp. 390-410, 2003.

[63] H. Garavan and J. C. Stout, "Neurocognitive insights into substance abuse," Trends in Cognitive Sciences, vol. 9, no. 4, pp. 195-201, 2005.

[64] US Department of Education, National Education Longitudinal Study of 1988: First Follow-Up Student Component Data File User's Manual, National Center for Educational Statistics, Washington, DC, USA, 1992.

[65] S. E. Siennick and J. Staff, "Explaining the educational deficits of delinquent youths," Criminology, vol. 46, no. 3, pp. 609-635, 2008.

[66] R. B. Felson and J. Staff, "Explaining the academic performancedelinquency relationship," Criminology, vol. 44, no. 2, pp. 299319, 2006.

[67] S. J. Jang, "Race, ethnicity, and deviance: a study of Asian and non-Asian adolescents in America," Sociological Forum, vol. 17, no. 4, pp. 647-680, 2002. 
[68] L. D. Johnston, P. M. O’Malley, J. G. Bachman, and J. E. Schulenber, "Demographic subgroup trends for various licit and illicit drugs, 1975-2009," Monitoring the Future Occasional Paper 73, Institute for Social Research, University of Michigan, Ann Arbor, Mich, USA, 2010.

[69] S. L. Pedersen, B. S. G. Moline, K. A. Belendiuk, and J. E. Donovan, "Racial differences in the development of impulsivity and sensation seeking from childhood into adolescence and their relation to alcohol use," Alcoholism, vol. 36, no. 10, pp. 1794-1802, 2012.

[70] M. R. Pemberton, J. D. Colliver, T. M. Robbins, and Gfoerer, "Underage alcohol use: findings from the 2002-2006 national surveys on drug use and health," DHHS Publication SMA 084333, Analytic Series A-30, Substance Abuse and Mental Health Services Administration, Office of Applied Statistics, Rockville, Md, USA, 2008.

[71] R. Paternoster, R. Brame, P. Mazerolle, and A. Piquero, "Using the correct statistical test for the equality of regression coefficients," Criminology, vol. 36, no. 4, pp. 859-866, 1998.

[72] R. Agnew, "Foundation for a general strain theory of crime and delinquency," Criminology, vol. 30, no. 1, pp. 47-86, 1992.

[73] R. Agnew, "Building on the foundation of general strain theory: specifying the types of strain most likely to lead to crime and delinquency," Journal of Research in Crime and Delinquency, vol. 36, pp. 123-155, 2001.

[74] R. Agnew, Pressured Into Crime: An Overview of General Strain Theory, Roxbury, Los Angeles, Calif, USA, 2006.

[75] A. K. Cohen, Delinquent Boys: The Culture of the Gang, The Free Press, Glencoe, UK, 1955.

[76] R. K. Merton, Social Theory and Social Structure, The Free Press, A Division of Simon and Schuster, New York, NY, USA, 1968.

[77] T. Hirschi, Causes of Delinquency, University of California Press, Berkeley, Calif, USA, 1969.

[78] J. P. Wright and F. T. Cullen, "Parental efficacy and delinquent behavior: do control and support matter?" Criminology, vol. 39, no. 3, pp. 677-706, 2001. 

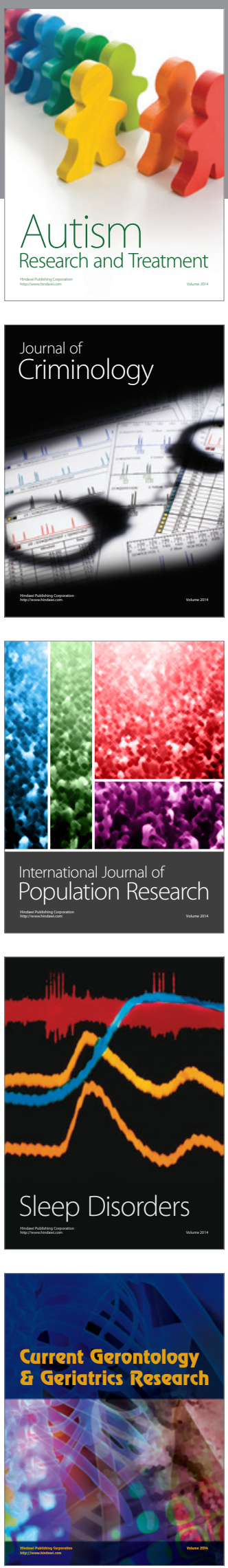
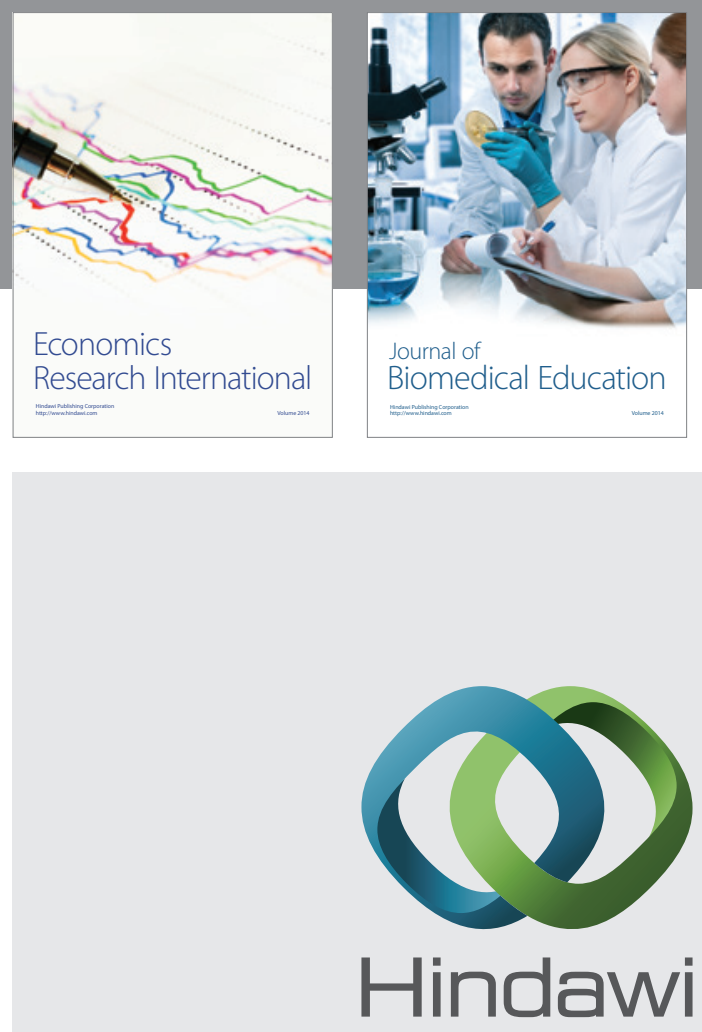

Submit your manuscripts at

http://www.hindawi.com
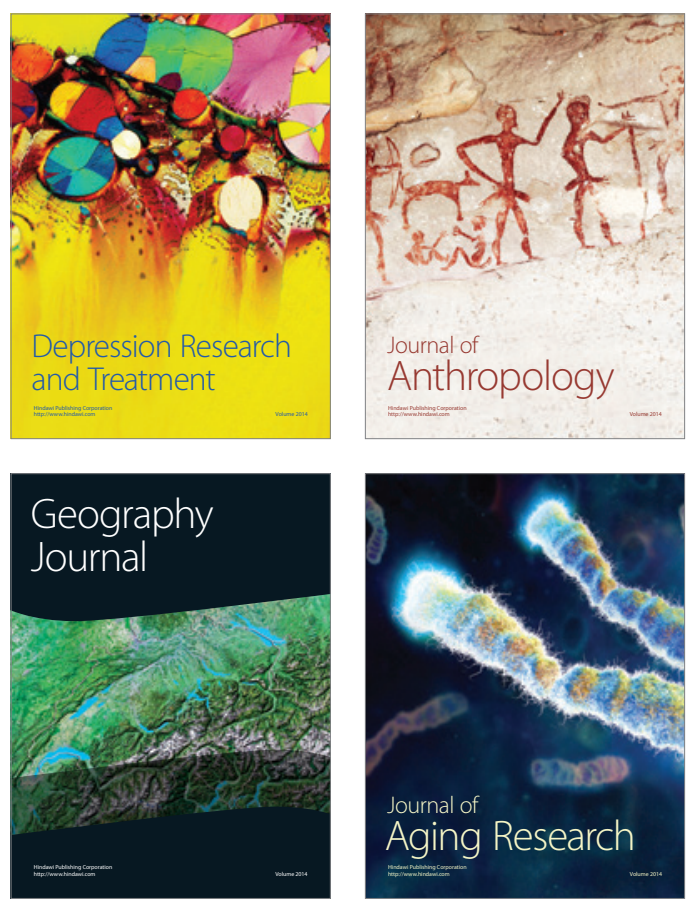
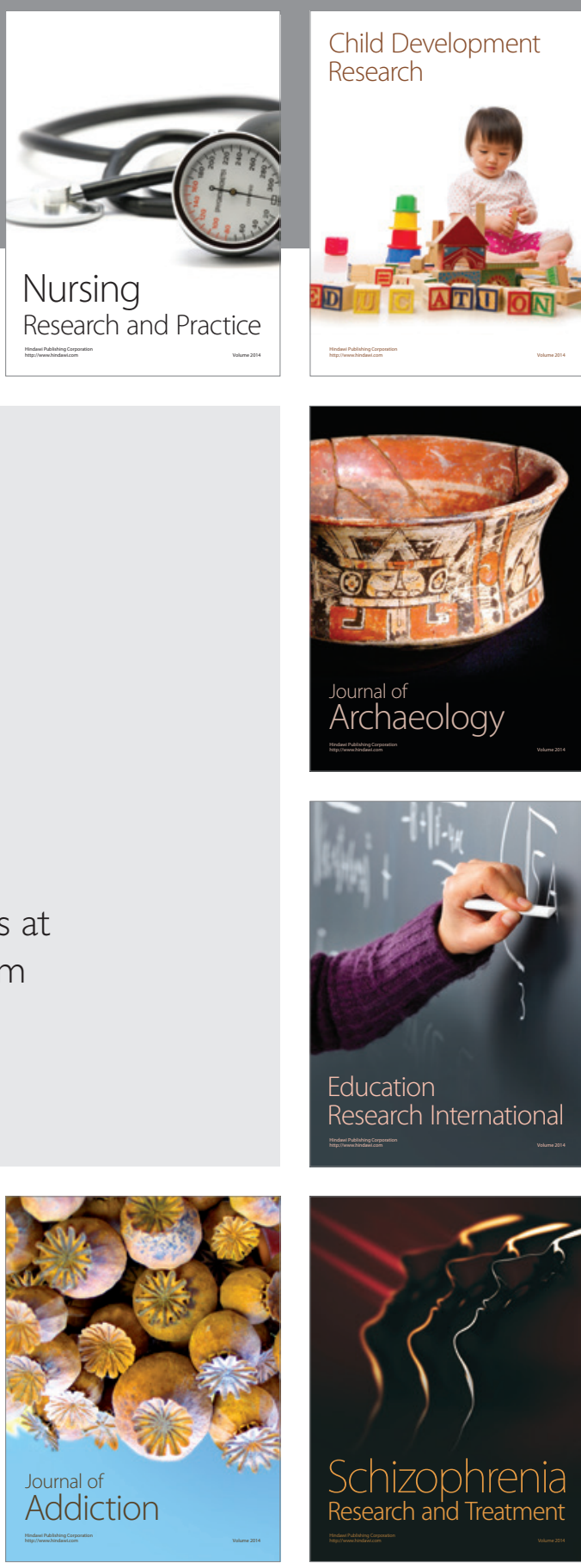

(D)
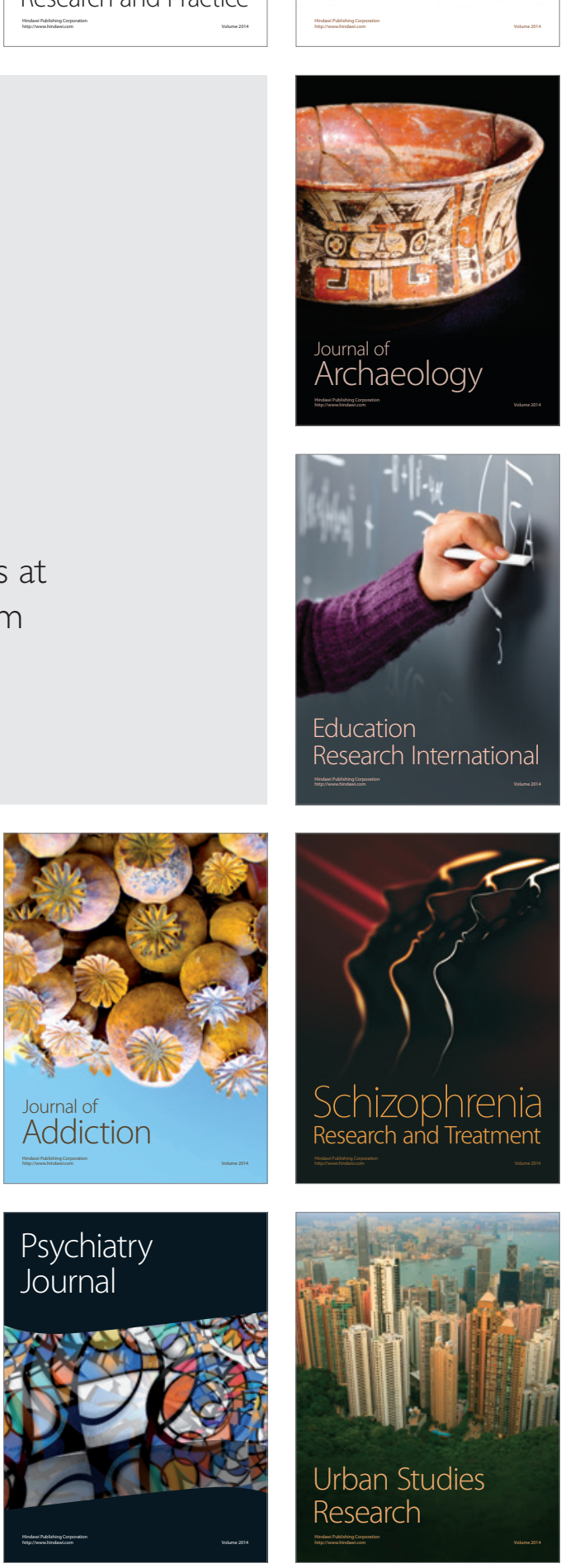